Article

\title{
Co-Delivery of Eugenol and Dacarbazine by Hyaluronic Acid-Coated Liposomes for Targeted Inhibition of Survivin in Treatment of Resistant Metastatic Melanoma
}

\author{
Harshita Mishra ${ }^{1}$, Pawan Kumar Mishra ${ }^{2} \oplus$, Zeenat Iqbal ${ }^{1}$, Manu Jaggi ${ }^{3}$, Alka Madaan ${ }^{3}$, \\ Kimi Bhuyan ${ }^{3}$, Namita Gupta ${ }^{3}$, Neha Gupta ${ }^{3}$, Karnika Vats ${ }^{3}$, Ritu Verma ${ }^{3}$ and \\ Sushama Talegaonkar 1,4,* \\ 1 Departmant of Pharmaceutics, School of Pharmaceutical Education and Research, Jamia Hamdard, \\ New Delhi 110062, India; harshitasharma1088@gmail.com (H.M.); zeenatiqbal@jamiahamdard.ac.in (Z.I.) \\ 2 Department of Wood Processing, Mendel University in Brno, 61300 Brno, Czech Republic; \\ pawan.mishra@mendelu.cz \\ 3 Dabur Research Foundation, Ghaziabad 201010, India; manu.jaggi@daburresearch.in (M.J.); \\ alka.madaan@daburresearch.in (A.M.); kimi.bhuyan@daburresearch.in (K.B.); \\ namita.gupta@daburresearch.in (N.G.); neha.gupta@daburresearch.in (N.G.); \\ karnika@daburresearch.in (K.V.); ritu.verma@daburresearch.in (R.V.) \\ 4 Department of Pharmaceutics, Delhi Pharmaceutical Sciences and Research University, \\ Govt. of NCT of Delhi, Pushp Vihar, New Delhi 110017, India \\ * Correspondence: stalegaonkar@jamiahamdard.ac.in; Tel.: +91-9818453518
}

Received: 28 January 2019; Accepted: 18 March 2019; Published: 3 April 2019

\begin{abstract}
While melanoma remains a challenge for oncologists, possibilities are being continuously explored to fight resistant metastatic melanoma more effectively. Eugenol is reported to inhibit survivin protein in breast cancer cells. Survivin is also overexpressed by melanoma cells, and is known to impart resistance to them against chemotherapy-induced apoptosis. To be able to fight resistant melanoma, we formulated hyaluronic acid (HA)-coated liposomes loaded with an effective combination of anti-melanoma agents (Dacarbazine and Eugenol), using a solvent injection method. Quality-by-Design (QbD) was applied to optimize and obtain a final formulation with the desired quality attributes, and within an acceptable size range. The optimized formulation was then subjected to performance analysis in cell lines. Coated-Dacarbazine Eugenol Liposomes were found to possess $95.08 \%$ cytotoxicity at a dacarbazine concentration of $0.5 \mu \mathrm{g} / \mathrm{mL}$, while Dacarbazine Solution showed only $10.20 \%$ cytotoxicity at the same concentration. The number of late apoptotic cells was also found to be much higher (45.16\% vs. $8.43 \%)$. Furthermore, migration assay and proliferation study also revealed significantly higher inhibition of cell migration and proliferation by Coated-Dacarbazine Eugenol Liposomes, signifying its potential against metastasis. Thus, surface-functionalized dacarbazine- and eugenol-loaded liposomes hold great promise against resistant and aggressive metastatic melanoma, with much less unwanted cytotoxicity and reduced doses of the chemotherapeutic agent.
\end{abstract}

Keywords: Quality by Design (QbD); liposomes; hyaluronic acid; melanoma treatment; survivin inhibition; cytotoxicity; apoptosis; migration inhibition

\section{Introduction}

Melanocytes, while, on the one hand, protecting the skin from harmful ultraviolet radiation in their normal state, form one of the deadliest cancers when undergoing malignant growth on the other. 
Melanoma, which is the cancer of melanocytes, is a highly aggressive cancer, and causes up to $60-80 \%$ of skin cancer-related deaths [1,2]. As another matter of concern, the incidence rates of melanoma are continuously on the rise, with an increase of around 56\% from 2005 to 2015 [3]. Furthermore, the median survival of metastatic melanoma (stage IV) patients is very poor, with no more than $10 \%$ of patients still being alive ten years after the treatment [4].

The major challenge associated with melanoma treatment is the resistance of melanoma cells chemotherapy, which can lead to the failure of the treatment, along with poor response and survival rates $[5,6]$. While several studies have been performed on the multidrug resistance of cancer cells $[7,8]$, the inherent resistance of melanoma cells is reported to be due to a protein named survivin. The survivin protein is a member of the inhibitor of apoptosis (IAP) family, and exerts its effects by directly inhibiting caspases $[9,10]$. Several cancer types, including melanoma, have been reported to overexpress survivin. Survivin protects cancer cells from apoptosis, which is supposed to be induced by chemotherapy in order to kill cancer cells. Survivin is also known to play an essential role in angiogenesis by promoting the expression of the vascular endothelial growth factor (VEGF) in cancer cells [11]. It is reported that inhibiting the function of survivin in melanoma cells can spontaneously cause apoptosis, impairing the growth of the tumor [12]. Downregulation of survivin has also been found to inhibit migration, metastasis, and proliferation of cancer cells, both in vitro and in vivo [13]. The fact that it is overexpressed in most cancer cells, but hardly expressed at all in any normal tissue, makes it an attractive target for targeted anti-cancer therapies [14].

Eugenol (4-allyl-1-hydroxy-2-methoxybenzene), the main constituent of clove (Syzygium aromaticum), has been shown to target and inhibit survivin in breast cancer cells, thus inducing apoptosis and tumor inhibition [15]. Additionally, eugenol has specifically shown anti-proliferative and apoptosis-inducing effects in melanoma in vitro and in vivo [16]. The presence of a hydroxyl group and an aromatic ring in the eugenol structure has been reported to be important for its anti-cancer action [17].

Nanotechnology has a special role in the treatment of cancer, because it enables scientists to specifically target the cancer cells with anti-cancer drugs, sparing normal tissues, and avoiding any unwanted side effects, which constitute the major drawback of chemotherapy [18,19]. Nanoagents loaded with chemotherapeutic drugs and surface-functionalized with ligands, have been formulated and successfully implemented in the treatment of melanoma [19-22]. However, the design and optimization of a formulation in the most effort-, time- and cost-effective manner have proven challenging for scientists. Here, the QbD (Quality by Design) approach comes to the rescue. QbD is a scientific and systematic approach for use in the development of pharmaceutical formulations. It involves defining and taking into consideration all of the parameters that critically affect the final quality and performance of the formulation. QbD can be focused on defining the aspects of quality that need to be optimized [23]. Application of QbD helps in understanding and establishing the relationship between the process parameters and the quality attributes of the formulation. It helps scientists understand how the critical process parameters should be varied in order to consistently produce a pharmaceutical formulation with the desired quality attributes [23,24].

Bearing the above-stated facts in mind, we formulated dual-loaded, surface-functionalized liposomes for the targeted anti-resistance therapy of melanoma. Dacarbazine, an alkylating chemotherapeutic agent, is still the mainstay of melanoma treatment, and it forms the basis for most anti-melanoma combinations [4]. Dacarbazine is combined with eugenol for its survivin-targeting ability. Both drugs are loaded in liposomes, and liposomes are finally surface-functionalized with Hyaluronic acid (HA) in order to enable the active targeting of CD44 receptors, which are overexpressed by cancer cells [25].

In this case, since two drugs were to be loaded into the liposomes, the QbD was applied on two levels. On the first level, single drug (dacarbazine)-loaded liposomes were optimized, and on the second level, dual-loaded (Dacarbazine + Eugenol) liposomes were optimized by fixing several parameters based on the results of the first-level QbD. Applying QbD on two levels, and optimizing all 
the independent variables in a two-step $\mathrm{QbD}$ approach, rather than one, made the whole process more cost-effective and more reproducible.

\section{Materials and Methods}

Chemicals: Dacarbazine was kindly provided by Intas Pharmaceuticals (Ahmedabad, India). Eugenol (99.9\%) was purchased from Sigma Aldrich (St Louis, MO, USA). Lipoid S100 was a generous gift from Lipoid GmbH, Frigenstr. 4, 67065 Ludwigshafen, Germany. All other reagents used were of analytical grade and were used without any further purification.

Cell Lines: Cell line studies were carried out in the Cell Biology Department, Dabur Research Foundation, Ghaziabad, India. SK-MEL-28 and B16F10 melanoma cell lines were procured from the National Center for Cell Science (NCCS, Pune, India); The EA.hy.926 cell line was procured from the American Type Culture Collection (ATCC, Rockville, MD, USA).

\subsection{Synthesis of Liposomes}

Liposomes were synthesized by a solvent injection method using ethanol as the organic solvent [26]. Lipid and cholesterol were dissolved in ethanol. This constituted the organic phase. Then the eugenol was dissolved in this organic phase because of its lipophilic nature. Separately, dacarbazine was dissolved in distilled water, which constituted the aqueous phase. This aqueous phase was then kept on stirring (1000 rpm), and the organic phase was rapidly injected into it using a syringe of $1 \mathrm{~mL}$ capacity, and a 24 gauge needle size. The volume of ethanol was fixed at $5 \mathrm{~mL}$. Figure 1 gives a pictorial representation of the method of preparation of dual drugs-loaded liposomes.

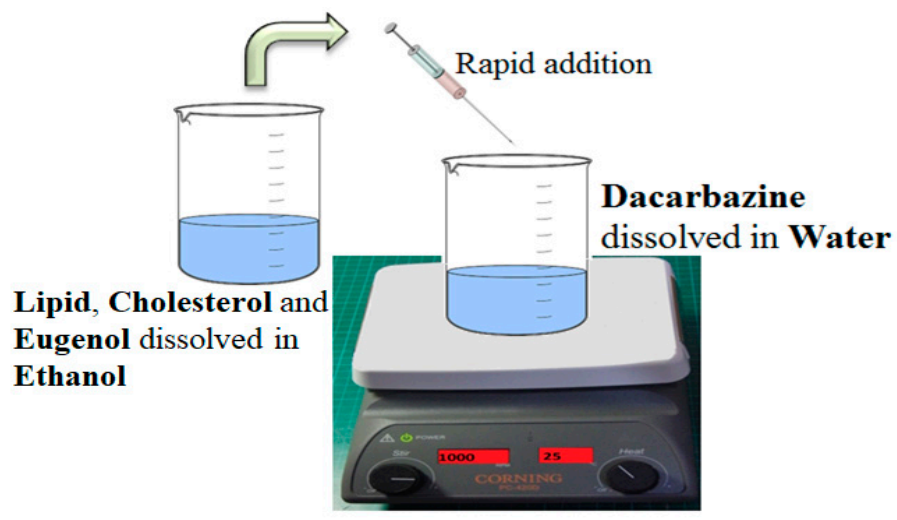

Figure 1. Method of Preparation of dual loaded Liposomes. An ethanolic solution of lipid, cholesterol and the lipophilic drug is rapidly injected into an aqueous solution of a hydrophilic drug, under stirring. Spontaneous formation of liposomes takes place.

\subsection{Optimization of Formulation: Quality-by-Design ( $Q b D)$}

To synthesize the dual loaded liposomes with optimum parameters, Central Composite Design (CCD) was chosen and applied using Design Expert ${ }^{\circledR}$ version 11.0.0 by Stat-Ease, Inc. (Suite 480, Minneapolis, MN, USA). (CCD) was selected for the optimization of the formulation because it generates a greater number of runs as compared to other designs in the Design Expert software [27]. Since the formulation had to be loaded with two drugs and specific characteristics were desired, the central composite design was applied at two levels.

Each variable was set at low (-1) and high (1) levels. The software itself took a middle value (0) also, and generated combinations with three different values, -1 (low), 0 (medium) and +1 (high). 


\subsubsection{First Level}

Initial Risk Assessment

Critical quality attributes (CQAs) are the quality aspects of the final product which are critical for its performance, and are to be optimized. In the present study, particle size and entrapment efficiency were selected as CQAs for initial risk assessment. Critical material attributes (CMAs) and critical process parameters (CPPs) are the material and process variables, respectively, that are expected to affect and alter the quality (CQAs) of the final formulation.

According to the literature surveyed and results of the preliminary experiments, various CMAs and CPPs were identified, namely:

CMAs: Lipid concentration, Drug concentration, Lipid: Cholesterol

CPPs: Water: Ethanol, Stirring speed, Stirring time

The effect of all these CMAs and CPPs was assessed to identify the intensity of their impact, and the appropriate range of each variable. The conclusions are summarized in Table 1.

Table 1. Initial Risk Assessment (First level).

\begin{tabular}{cccc}
\hline \multirow{2}{*}{ Variables } & \multicolumn{2}{c}{ Relative Impact on CQAs } & \multirow{2}{*}{ Suitable Range } \\
\cline { 2 - 3 } & Size & Entrapment Efficiency & \\
\hline CMAs & & & $10 \mathrm{mg} / \mathrm{mL}-30 \mathrm{mg} / \mathrm{mL}$ \\
Lipid Concentration & High & Medium & $1 \mathrm{mg}-3 \mathrm{mg}$ \\
Drug Concentration & Medium & High & 2 \\
Lipid: Cholesterol & Low & Medium & \\
\hline CPPs & & & $3-5$ \\
Water: Ethanol & High & Medium & $1000 \mathrm{rpm}$ \\
Stirring speed & Medium & Low & $60 \mathrm{~min}$ \\
Stirring time & Low & Low &
\end{tabular}

\section{Design of the Experiment}

The first level design of experiment (DOE) was applied first to optimize single drug (dacarbazine)-loaded liposomes to select the optimum lipid concentration and waterethanol ratio to synthesize liposomes with minimum size and good entrapment of the base drug, i.e., dacarbazine.

As stated in Table 2, three independent variables (denoted as Factors) were selected. Factor 1 was Lipid concentration $(\mathrm{mg} / \mathrm{mL})$, i.e., amount of lipid to be taken and dissolved in ethanol. Low level $(-1)$ was fixed at $10 \mathrm{mg} / \mathrm{mL}$, and high level $(+1)$ was fixed at $30 \mathrm{mg} / \mathrm{mL}$. Factor 2 was the water:ethanol ratio, with a low-level value of $3(-1)$, and a high-level value of $5(+1)$. Factor 3 was the drug concentration, i.e., the amount of dacarbazine that needs to be dissolved in water. The values selected for this drug concentration were $1 \mathrm{mg} / \mathrm{mL}$ (low level, -1 ) and $3 \mathrm{mg} / \mathrm{mL}$ (high level, +1 ). Two dependent variables (final characteristics of the formulation, denoted as Responses) were selected, which were the main criteria for the suitability of the formulations. Response 1 was size, and response 2 was entrapment efficiency of the dacarbazine.

The lipid:cholesterol ratio, stirring speed and stirring time were taken as fixed variables. By preliminary analysis of factors affecting the formulation outcomes, stirring time and stirring speed were fixed at $60 \mathrm{~min}$ and $1000 \mathrm{rpm}$ respectively, as it was found that these values produced optimum results. The lipid:cholesterol ratio was also fixed at 2 , in accordance with the results obtained in the preliminary studies. 
Table 2. Design of Experiment (DOE) Variables (First level).

\begin{tabular}{cccc}
\hline Independent Variables & \multicolumn{3}{c}{ Levels } \\
\cline { 2 - 4 } & $\mathbf{- 1}$ & $\mathbf{0}$ & $\mathbf{+ 1}$ \\
\hline Factor 1: Lipid Concentration $(\mathrm{mg} / \mathrm{mL})$ & 10 & 20 & 30 \\
Factor 2: Water:Ethanol & 3 & 4 & 5 \\
Factor 3: Drug Concentration $(\mathrm{mg} / \mathrm{mL})$ & 1 & 2 & 3 \\
\hline Dependent Variables & \multicolumn{3}{c}{ Constraints } \\
\hline Response 1: Size $(\mathrm{nm})$ & Minimum \\
Response 2: Entrapment Efficiency $(\%)$ & Maximum \\
\hline Fixed Variables & Fixed Values \\
\hline Stirring Time & 60 min \\
Stirring Speed & 1000 rpm \\
Cholesterol: Lipid & \multicolumn{3}{c}{. }
\end{tabular}

\subsubsection{Second Level}

\section{Initial Risk Assessment}

In addition to the variables fixed previously, lipid concentration and water:ethanol ratio were also fixed in the second level CCD. The values of these two factors were fixed at the optimum values as suggested by the first level CCD. All values are summarized in Table 3.

Table 3. DOE Variables (Second level).

\begin{tabular}{cccc}
\hline Independent Variables & \multicolumn{3}{c}{ Levels } \\
\cline { 2 - 4 } & $\mathbf{- 1}$ & $\mathbf{0}$ & $\mathbf{+ 1}$ \\
\hline Factor 1: Dacarbazine Concentration $(\mathrm{mg} / \mathrm{mL})$ & 1 & 2 & 3 \\
Factor 2: Eugenol Concentration $(\mathrm{mg} / \mathrm{mL})$ & 5 & 7.5 & 10 \\
\hline Dependent Variables & \multicolumn{3}{c}{ Constraints } \\
\hline Response 1: Size $(\mathrm{nm})$ & Minimum \\
Response 2: Eugenol:Dacarbazine & Maximum \\
\hline Fixed Variables & Fixed Values \\
Lipid Concentration & 13.168 mg/mL \\
Water: Ethanol & 5 \\
Stirring Time & $60 \mathrm{~min}$ \\
Stirring Speed & \multicolumn{3}{c}{$1000 \mathrm{rpm}$} \\
Cholesterol:Lipid & \multicolumn{3}{c}{}
\end{tabular}

Design of Experiment

Second level DOE was applied to determine the right concentration of both of the drugs to be taken in order to produce liposomes with the minimum size and a maximum ratio of entrapped eugenol to entrapped dacarbazine (Eugenol:Dacarbazine). Two independent variables (factors) were selected; Factor 1 was a concentration of dacarbazine, and Factor 2 was the concentration of eugenol. The fixed values of Factor 1 and Factor 2 are shown in Table 3.

Three-dimensional response surface plots were obtained using the software to illustrate the effect of selected factors (independent variables) on the responses (dependent variables). Analysis of Variance (ANOVA) was applied to the obtained responses. The equations for each independent variable were generated by using the values of its coefficients.

The values of responses obtained were fitted into different models, namely, linear, two-factor interaction (2F1), quadratic and cubic models. Based on the data obtained from the lack of fit tests 
and model summary statistics, a suitable model was selected and applied. Constraints were applied on dependent variables, and optimized formulation with the highest desirability factor was selected using the numerical technique.

\subsection{Surface Functionalization}

To actively target the liposomes to cancer cells, the surface of optimized dual loaded liposomes was coated with hyaluronic acid (HA), which has a particular affinity for CD44 receptors that are overexpressed by most of the cancer cell lines. HA is anionic due to the presence of carboxyl groups, and to employ the ionic interaction method for coating, the liposomes had to have a cationic surface. The liposomes prepared using Lipoid S100 were anionic, and had a negative surface charge as revealed by zeta potential studies. So, to make cationic liposomes, CTAB (cetyl tetra ammonium bromide) was used. Briefly, $10 \mathrm{mg}$ of CTAB was dissolved along with lipid, cholesterol, and eugenol in the ethanol. This ethanolic phase was added to an aqueous phase containing dacarbazine under stirring. The ethanol was later evaporated to obtain drugs-loaded cationic liposomes.

Separately, HA solutions of four different concentrations $(0.005 \%, 0.01 \%, 0.05 \%, 0.1 \%)$ were prepared by dissolving certain quantities of HA in water, and stirring for $60 \mathrm{~min}$. To coat the HA on liposomes, $10 \mathrm{~mL}$ of optimized cationic liposomal suspension was added into $5 \mathrm{~mL}$ of the HA solution. The addition was done under stirring, and stirring was continued for four hours [28].

\subsection{Particle Size, Size Distribution, and Zeta Potential}

Blank liposomes, dual loaded liposomes, and dual loaded surface-coated liposomes were scanned for the said parameters. The mean particle size, poly dispersity index (PDI) and zeta potential of the different liposomes were determined by dynamic light scattering using a particle size analyzer (Delsa ${ }^{\mathrm{TM}}$ Nano C, Beckman Coulter Counter, Brea, CA, USA). The liposomal suspension was diluted ten times using deionized water, and this diluted suspension was put into the particle size analyzer to obtain the results [29].

\subsection{Electron Microscopy}

To confirm the size of the liposomes and ascertain the successful coating on the surface, electron microscopic analysis was performed. For Scanning Electron Microscopy (SEM), the sample was coated with gold, and then kept in the sampling unit as a thin film. The photographs were taken at different magnifications using a Scanning Electron Microscope (Jeol, Tokyo, Japan) [30]. For Transmission Electron Microscopy (TEM), a drop of this sample was deposited onto a copper grid coated with fomvar. The grid was then immersed in one drop of $2 \%$ phosphotungstic acid for $20 \mathrm{~s}$ and then was allowed to dry. The grid was finally observed under Transmission Electron Microscopy (Tecnai, G20, FEI, Eindoven, The Netherlands).

\subsection{Drug Loading and Entrapment Efficiency}

To determine the loading of drugs in the synthesized liposomes, the liposomal suspension was centrifuged at 36,000 rpm (Beckman Coulter, Optima ${ }^{\mathrm{TM}} \mathrm{L}-100 \mathrm{~K}$, London, United Kingdom) to remove the unentrapped drugs. The supernatant which contained unentrapped drugs was separated, and the pellets of liposomes were dissolved in ethanol. Ethanol, which could dissolve the lipid as well as both drugs, was a suitable solvent for the determination of drug loading. Since a simultaneous loading of two drugs was to be determined, a novel UV absorptivity method (Shimadzu, Kyoto, Japan) for simultaneous determination of the drugs, was developed by the authors. The ethanolic solution of drugs-loaded liposomes was suitably diluted, and its absorbance was measured at $\lambda_{1}$ et $\left(\lambda_{\max }\right.$ of dacarbazine in ethanol, i.e., $333 \mathrm{~nm})$ and $\lambda_{2}{ }^{\text {et }}\left(\lambda_{\max }\right.$ of eugenol in ethanol, i.e., $\left.282.5 \mathrm{~nm}\right)$ against an ethanolic solution of unloaded liposomes as blank. These absorbance values $\left(\mathrm{A}_{1}{ }^{\text {et }}\right.$ and $\left.\mathrm{A}_{2}{ }^{\text {et }}\right)$ were put into Equations (1) and (2) which were generated by the absorptivity method. 


$$
\begin{aligned}
& \mathrm{A}_{1}{ }^{\text {et }}=1005 \mathrm{C}_{\mathrm{d}}{ }^{\text {et }}+72.24 \mathrm{C}_{\mathrm{e}}{ }^{\text {et }} \\
& \mathrm{A}_{2}{ }^{\text {et }}=616 \mathrm{C}_{\mathrm{d}}{ }^{\text {et }}+144.21 \mathrm{C}_{\mathrm{e}}{ }^{\text {et }}
\end{aligned}
$$

After solving the simultaneous equations, amount of dacarbazine and amount of eugenol present in the formulation were determined by multiplying the concentration of dacarbazine $\left(\mathrm{C}_{\mathrm{d}}{ }^{\mathrm{et}}\right)$ and the concentration of eugenol $\left(\mathrm{C}_{\mathrm{e}}{ }^{\mathrm{et}}\right)$ with dilution factors. formula:

Drug loading of the formulation with respect to both drugs was calculated by using the following

Drug Loading $(\%)=($ Amount of drug present in formulation/Total weight of the formulation $\times 100)$

After determining the amount of drugs present in the liposomes, the entrapment efficiency of both drugs was calculated by the following formula:

Entrapment efficiency $(\%)=($ Amount of drug entrapped/Total amount of drug used $) \times 100$

\subsection{In Vitro Drug Release}

The in vitro release study of dual loaded surface-functionalized liposomes was carried out throughout $72 \mathrm{~h}$, using the dialysis bag method [31]. Phosphate Buffer Saline (PBS) (pH 7.4): Propylene glycol (9:1) was used as a release medium because both the drugs were soluble in this media, while the lipid was insoluble. The dialysis membrane (MW cut off $8-10 \mathrm{kDa}$; Spectra/Por ${ }^{\circledR}$ Spectrum Laboratories, Inc., Visalia, CA, USA) was activated before using as per the instructions given on the packaging. The liposomal suspension was centrifuged as described above. The supernatant was discarded, and pellets were dispersed in $10 \mathrm{~mL}$ of release media. This dispersion was put in a dialysis bag, and the bag was suspended in $200 \mathrm{~mL}$ of receiving phase i.e., PBS (pH 7.4): Propylene glycol (9:1), and placed into an incubator shaker maintained at $37^{\circ} \mathrm{C}$ and $100 \mathrm{rpm}$. Aliquots each of $3 \mathrm{~mL}$ were withdrawn at various time points (up to $72 \mathrm{~h}$ ). The same volume $(3 \mathrm{~mL})$ of the media was replaced after each sampling to maintain the sink condition during the study. The absorbance of samples withdrawn at different time points (and suitably diluted when needed), was measured at $\lambda_{1}\left(\lambda_{\max }\right.$ of dacarbazine in release media, i.e., $331 \mathrm{~nm})$ and $\lambda_{2}\left(\lambda_{\max }\right.$ of eugenol in release media, i.e., $\left.281.5 \mathrm{~nm}\right)$ against pure release media as blank. These absorbance values $\left(A_{1}\right.$ and $\left.A_{2}\right)$ were put into Equations (3) and (4), which were generated by an absorptivity method developed in house using PBS: Propylene glycol (9:1) as a solvent.

$$
\begin{aligned}
& A_{1}=949.64 C_{d}+30.59 C_{e} \\
& A_{2}=319.93 C_{d}+138.36 C_{e}
\end{aligned}
$$

After solving the above simultaneous equations, the amount of both the drugs $\left(C_{d}\right.$ and $\left.C_{e}\right)$ present in the release media at different time points was calculated.

$\%$ Release at any point of time $=($ Amount of drug present in the release media/Total amount of drug present in formulation/dialysis bag) $\times 100$

\subsection{Stability Study}

To check the stability of the final formulation, the liposomes were lyophilized and stored under refrigeration $\left(4^{\circ} \mathrm{C}\right)$ for four weeks. The particle size, PDI and drug content of the liposomes were determined at the end of every week by dispersing in PBS (7.4) to assess the storage stability of the liposomes. Stability of the liposomes was also assessed in cell culture media (Eagle's minimal essential medium (DMEM) $+10 \%$ FBS) for three days. 


\subsection{Cell Line Studies}

Growth medium used for cell lines was DMEM $+10 \%$ FBS. Growth conditions were $37^{\circ} \mathrm{C}, 95 \%$ Humidity, $5 \% \mathrm{CO}_{2}$. Sub-culturing was done once the cells were $80-90 \%$ confluent in the T-75 culture flask. Untreated cells with complete medium (10\% FBS) served as our complete medium control, cells with sera free medium (SFM) served as an SFM control, and the cells treated with Paclitaxel/Doxorubicin served as the Positive control.

\subsubsection{MTT Assay}

The MTT assay was first performed on the SK-MEL-28 melanoma cell line using the previously reported method [31]. The four samples tested were blank liposomes (BL), Dacarbazine solution (DS), Dacarbazine Liposomes (DL), and Dacarbazine + Eugenol Liposomes (DEL). To perform the assay on above-said test samples, cells were plated at a density of 0.5 million/well in 6-well culture plates, and were incubated for $24 \mathrm{~h}$ in a $\mathrm{CO}_{2}$ incubator. $20 \mu \mathrm{L}$ of $5 \mathrm{mg} / \mathrm{mL}$ of MTT 3-(4,5-dimethythiazol-2-yl)-2,5-diphenyl tetrazolium bromide solution was added to all the wells, followed by additional incubation for three $\mathrm{h}$ at $37^{\circ} \mathrm{C}$. The supernatant was aspirated, and $150 \mu \mathrm{L}$ of dimethyl sulfoxide (DMSO) was added to each well to dissolve the formazan crystals. The absorbance of each well was then read at $540 \mathrm{~nm}$ using a Synergy HT micro plate-reader.

The percentage cytotoxicity corresponding to each treatment was calculated using the following formula:

$$
\% \text { Cytotoxicity }=[R-X) / R] \times 100
$$

where $X=$ Absorbance of wells corresponding to treated cells; $R=$ Absorbance of untreated cells (cells maintained in DMEM $+10 \%$ FBS).

Furthermore, in addition to the above said formulations, the cytotoxicity of final coated Dacarbazine + Eugenol Liposomes (DELC) was assessed in B16F10 melanoma cells using the same procedure as described.

\subsubsection{Apoptosis Assay}

Apoptosis profile of the SK-MEL-28 cells treated with formulations was studied by flow cytometry using Annexin V. Growth medium and growth conditions were kept the same as before. Cells were plated at a density of 0.5 million/well in 6-well culture plates, and were incubated for $24 \mathrm{~h}$ in a $\mathrm{CO}_{2}$ incubator. Cells were sera starved in DMEM $+0 \%$ FBS for four hours, and were then treated with test samples (DS, DL, DEL, Coated Dacarbazine Liposomes (DLC), and DELC) for $24 \mathrm{~h}$. After $24 \mathrm{~h}$, cells were processed for Annexin V assay as follows: Cells were harvested very gently by trypsinization and centrifuged at $300 \mathrm{~g}$ for 5-7 min. The cell pellet was resuspended in 200-300 $\mu \mathrm{L}$ of Phosphate Buffer Saline (PBS). $100 \mu \mathrm{L}$ of cell suspension was transferred into pre-labeled tubes for staining. $100 \mu \mathrm{L}$ of Nexin reagent (Annexin V/7-AAD, Guava technologies, Merck millipore, Danvers, MA, USA) was added to each tube and mixed gently. Samples were incubated for $20 \mathrm{~min}$ at room temperature in the dark. Samples were then acquired on a flow cytometer (Guava Technologies, Hayward, California, USA).

\subsubsection{Migration Assay}

Cell migration analysis was done by the wound healing method on Ea.Hy293 cells. EA.hy926 cells were counted using a hemocytometer and plated in 12-well plates at the density of $0.2 \times 10^{6}$ cells/well in medium $+10 \%$ FBS. The cells were incubated overnight in the $\mathrm{CO}_{2}$ incubator to allow cell recovery and exponential growth. Following overnight incubation, these cells were sera starved (DMEM + $0 \% \mathrm{FBS}$ ) for six $\mathrm{h}$. After six $\mathrm{h}$, the cells were washed with PBS, and a small linear scratch (representative wound) was created in the confluent monolayer (middle of the well) by gently scraping with sterile $200 \mu \mathrm{L}$ micropipette tip. Photomicrographs of the scratch were taken at $0 \mathrm{~h}$ (Initial time point). Cells 
were rinsed with serum-free DMEM and grouped for treatment with test samples (DS, DL, DEL, DLC, DELC). Photomicrographs of the scratch were taken at $0 \mathrm{~h}, 24 \mathrm{~h}, 48 \mathrm{~h}$, and $72 \mathrm{~h}$.

The photomicrographs obtained were analyzed for quantitative assessment of the area of wound closure using ImageJ tool software. Percentage migration with respect to untreated cells at different time points was calculated using the following formula:

$$
\% \text { Migration }=[(\text { MigrationUntreated }- \text { MigrationSample }) / \text { MigrationUntreated }] \times 100
$$

The extent of inhibition in cell migration with respect to untreated cells at different time points was calculated using the following formula:

$$
\% \text { Inhibition }=100 \%-\% \text { Migration of Untreated sample }
$$

\subsubsection{Proliferation Assay}

A proliferation assay also was performed on EA.hy926 cells. After sub culturing, the cells were counted using the hemocytometer and plated in 96 well plates at the density of $1 \times 10^{5}$ cells/well/180 $\mu \mathrm{L}$ of the growth medium with $10 \%$ FBS. After $24 \mathrm{~h}$ of incubation in a $\mathrm{CO}_{2}$ incubator, these cells were sera starved by replacing the medium with $0 \%$ FBS. The cells were incubated for $24 \mathrm{~h}$. After $24 \mathrm{~h}$, they were separately treated with 5 test items (DS, DL, DEL, DLC, DELC) at different concentrations in medium $+10 \%$ FBS. After three days of incubation, the effect of test formulations on cell proliferation was determined by calculating the \% viability of cells using MTT assay. Serum-free media control cells were assessed with respect to complete medium control cells.

\subsection{Statistical Analysis}

All the experiments were performed in triplicate. Excel ${ }^{\mathrm{TM}}$ program 2010 (Microsoft $^{\mathrm{TM}}, 36$ Redmond, $^{-}$ WA, USA) was used to calculate the mean \pm standard deviation of the obtained data. Data are presented as the mean \pm standard deviation (SD). All statistical analyses were carried out with Statistica 13 (TIBCO Software Inc., Palo Alto, CA, USA), using one-way Analysis of Variance (ANOVA) and Tukey's HSD as the posthoc test. All differences were considered significant at $p<0.05$.

\section{Results and Discussion}

\subsection{Synthesis}

As mentioned earlier, the liposomes were synthesized by solvent injection method. As per the experiments conducted by [32], this solvent injection method produces smaller-sized liposomes with comparatively higher encapsulation efficiencies of the entrapped drug. Lasic [33] had explained the bilayer planar fragments (BPFs) theory for the mechanism of formation of liposomes by the ethanol injection method. According to this theory, the lipids which are dissolved in ethanol precipitate at the phase boundary of water and ethanol (organic solvent), resulting in the formation of BPFs. When the organic solvent is completely diffused in the external aqueous phase, vesicle formation takes place consequent to self-assembly of BPFs.

\subsection{Optimization Using $Q b D$}

The formulation was optimized by following the QbD approach. QbD is a more economical and time effective method, and thus has replaced the hit and trial method for formulation optimization [27]. DOE (Design of Experiment) is an integral part of the QbD approach, which involves the use of the software to generate "structured" data tables. The software enables us to obtain a graphical interpretation of the results and effect of each parameter on the critical quality attributes (CQAs) of the formulation. Central composite design (CCD) was chosen because it generates better factorial design. Also, CCD can be used for working on factors as small as two in number. 


\subsubsection{First Level}

At the first level, only ardacarbazine-loaded liposomes were prepared and optimized in order to find out the optimum value of lipid concentration and water:ethanol ratio. CQAs selected were the size of the liposomes and the entrapment efficiency of the drug as both these are crucial parameters significantly influencing the performance of the formulation.

After putting minimum and maximum values of the independent variables into the CCD statistical experimental design, the software suggested 20 runs with five center points. These 20 formulations were prepared, analyzed, and the obtained values of dependent variables for each run were put into the table (Table 4). Software-generated polynomial equations, which could predict the effect of individual factors (independent variables), as well as combinations of factors on the responses (dependent variables).

Table 4. Response Analysis Data (Level 1). Values of Response 1 and Response 2 for 20 different combinations of Factor 1, Factor 2 and Factor 3.

\begin{tabular}{|c|c|c|c|c|c|}
\hline & Factor 1 & Factor 2 & Factor 3 & Response 1 & Response 2 \\
\hline 1 & 20 & 4 & 2 & $83.4 \pm 2.61$ & $25.85 \pm 0.82$ \\
\hline 2 & 10 & 5 & 1 & $65 \pm 2.12$ & $18.7 \pm 0.24$ \\
\hline 3 & 20 & 4 & 2 & $84.75 \pm 3.5$ & $24.57 \pm 0.6$ \\
\hline 6 & 20 & 4 & 1 & $72.6 \pm 2.73$ & $22.82 \pm 0.23$ \\
\hline 7 & 30 & 3 & 3 & $113.56 \pm 3.21$ & $31.67 \pm 1.24$ \\
\hline 8 & 10 & 5 & 3 & $70.7 \pm 1.75$ & $25.3 \pm 1.03$ \\
\hline 9 & 20 & 4 & 3 & $77.12 \pm 2.03$ & $27.4 \pm 0.78$ \\
\hline 10 & 20 & 3 & 2 & $83.4 \pm 2.3$ & $26.73 \pm 1.1$ \\
\hline 14 & 30 & 5 & 3 & $104.28 \pm 3.76$ & $20.82 \pm 0.42$ \\
\hline 15 & 10 & 3 & 3 & $78.4 \pm 1.24$ & $19.7 \pm 0.3$ \\
\hline 16 & 10 & 3 & 1 & $74.44 \pm 2.37$ & $11.14 \pm 1.0$ \\
\hline 17 & 30 & 5 & 1 & $99.38 \pm 3.5$ & $20.72 \pm 1.12$ \\
\hline 18 & 20 & 5 & 2 & $75.6 \pm 2.64$ & $23.5 \pm 1.45$ \\
\hline 19 & 20 & 4 & 2 & $82.15 \pm 2.35$ & $24.92 \pm 1.2$ \\
\hline 20 & 20 & 4 & 2 & $79.04 \pm 1.25$ & $25.16 \pm 0.96$ \\
\hline
\end{tabular}

Response Analysis for Optimization

Size of any nanoformulation is a crucial parameter, as it has major impacts on the performance, targeting ability and fate of the formulation in the body. Also, since finally, two drugs were to be loaded in the liposomes, and then coating was also to be done; the size of the liposomes had to be maintained at the minimum from the beginning. On fitting the resulted response data to various models, it was found that the data were best explained by the quadratic model. Summarized in Table 5, the Model $F$-value of 57.79 implies that the model is significant, indicating a considerably significant effect on dependent variables. $P$-values less than 0.0500 indicate that model terms are significant. The Lack of Fit $F$-value of 1.36 implies that the Lack of Fit is not significant relative to the pure error. Non-significant lack of fit is favorable. Value of Correlation Coefficient $\left(R^{2}\right)$ of 0.9811 suggested a good fit of the model as it approaches 1. Also, the Predicted $R^{2}$ of 0.9380 and the adjusted $R^{2}$ of 0.9642 are in reasonable agreement, i.e., the difference is less than 0.2 .

Equation (5) represents the effect of independent variables on the size of the final liposomes.

$$
\begin{aligned}
& \text { Size }=+81.07+17.60 \times A-4.40 \times B+2.34 \times C-0.2450 \times A B-0.0500 \times A C+0.2850 \times \\
& B C+11.59 \times A^{2}+0.4245 \times B^{2}-4.22 \times C^{2}
\end{aligned}
$$


This equation in terms of coded factors can be used to make predictions about the response for given levels of each factor. The coded equation is useful for identifying the relative impact of the factors by comparing the factor coefficients.

Table 5. Analysis of Variance (ANOVA) Analysis.

\begin{tabular}{ccccccccc}
\hline & \multicolumn{3}{c}{ Lack of Fit Tests } & \multicolumn{3}{c}{ Model Summary Statistics } \\
\hline Response & $\begin{array}{c}\text { Model } \\
\boldsymbol{F} \text {-Value }\end{array}$ & $\begin{array}{c}\text { Lack of Fit } \\
\boldsymbol{F} \text {-Value }\end{array}$ & $\boldsymbol{p}$-Value & SD & $\boldsymbol{R}^{2}$ & $\begin{array}{c}\text { Adjusted } \\
\boldsymbol{R}^{\mathbf{2}}\end{array}$ & $\begin{array}{c}\text { Predicted } \\
\boldsymbol{R}^{\mathbf{2}}\end{array}$ & $\begin{array}{c}\text { Suggested } \\
\text { Model }\end{array}$ \\
\hline R1: Size & 57.79 & 1.36 & $<0.0001$ & 2.72 & 0.9811 & 0.9642 & 0.9380 & Quadratic \\
\hline $\begin{array}{c}\text { R2: Entrapment } \\
\text { Efficiency }\end{array}$ & 70.71 & 2.48 & $<0.0001$ & 0.7394 & 0.9845 & 0.9706 & 0.9023 & Quadratic \\
\hline $\begin{array}{c}\text { Level 1 } \\
\text { R1: Size }\end{array}$ & 611.37 & 1.23 & $<0.0001$ & 2.09 & 0.9919 & 0.9903 & 0.9866 & Linear \\
\hline $\begin{array}{c}\boldsymbol{R} 2: \\
\text { Eugenol:Dacarbazine }\end{array}$ & 68.80 & 1.14 & 0.0489 & 0.0863 & 0.9803 & 0.9663 & 0.8992 & Quadratic \\
\hline
\end{tabular}

The mean size ranged from $65 \mathrm{~nm}$ to $113.56 \mathrm{~nm}$. The values of the coefficients of $\mathrm{A}, \mathrm{B}$, and C in the equation above suggest that the size of the liposomes is most influenced by the lipid concentration, followed by its water:ethanol ratio, and least affected by the drug concentration. The linear terms of lipid concentration and drug concentration have a positive effect on size, whereas the linear term of the water:ethanol ratio has a negative effect. Thus, the size of the liposomes increases with an increase in lipid concentration and drug concentration, and decreases with any increase in its water:ethanol ratio. Figure $2 \mathrm{a}-\mathrm{d}$ represents the effect of independent variables on the size of liposomes.

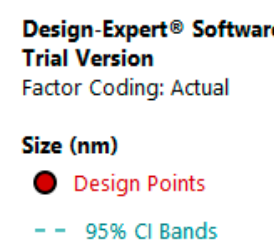

Actual Factors

A: Lipid Concentration $=20$

B: Water:Ethanol $=4$

C: Drug Concnetration $=2$
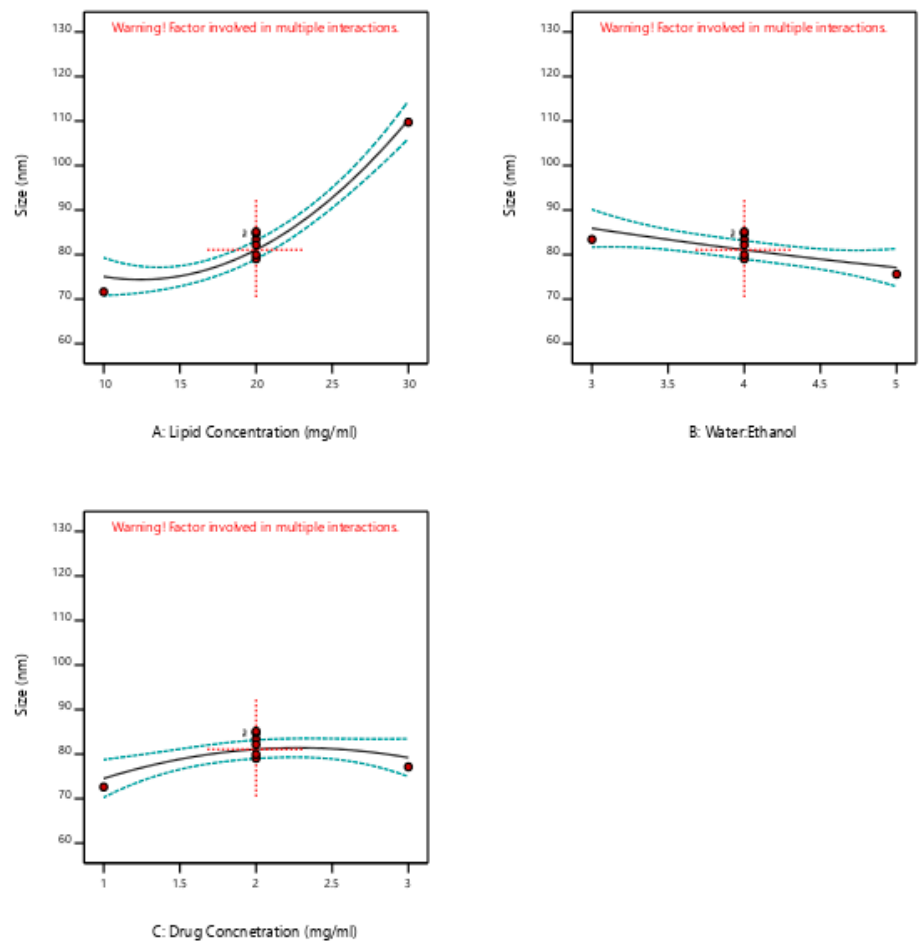

(a)

Figure 2. Cont. 


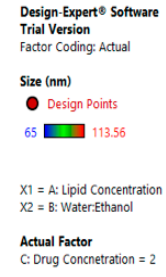

Actual Factor
C. Drug Concetration =

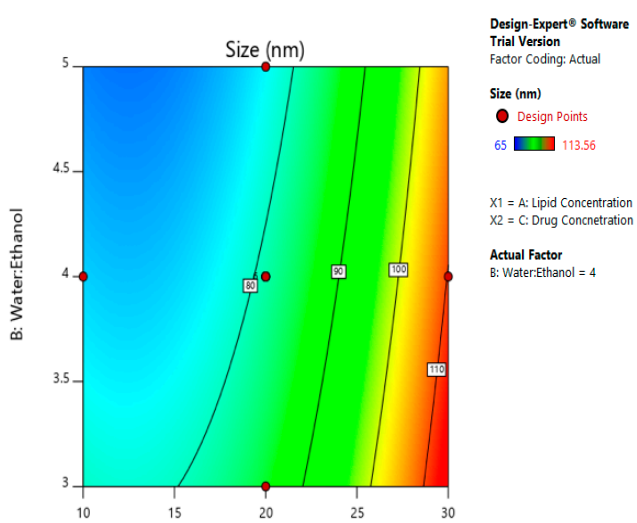

A: Lipid Concentration ( $\mathrm{mg} / \mathrm{ml}$ )

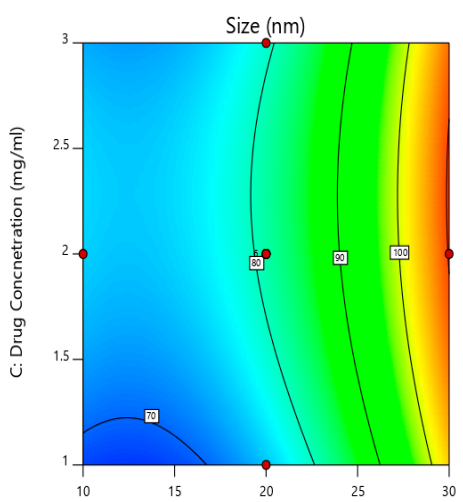

A: Lipid Concentration (mg/ml)
Design-Expert® Software
Trial Version

Factor Coding: Actua

Size $(n \mathrm{~m})$

- Design Points

$65 \square 113.56$

$x_{1}=B$ : Water:Ethanol

Actual Factor

A. Lipid Concentration $=20$

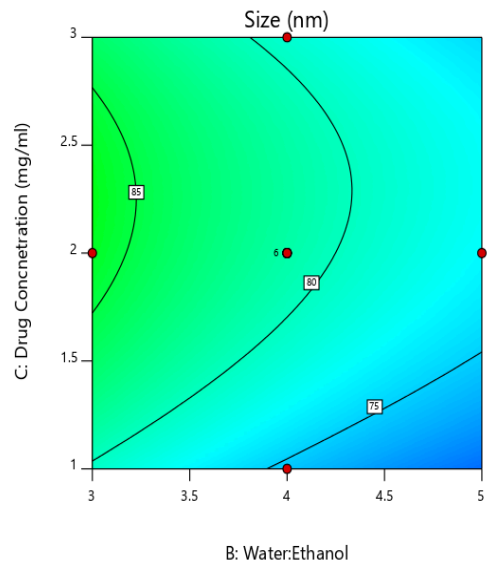

(b)
Design-Expert 6 Sottware

Trial Version

\section{Size (nn)}

- Design points above predited value

O Design points below preditted valus

$65 \square 113.56$

$X 1=$ A: Lipid Concentration
$X 2=B$ : WaterEFthanol

$x_{2}=8$ : Water. Ethano

Actual Factor

G. Drug concentration $=2$

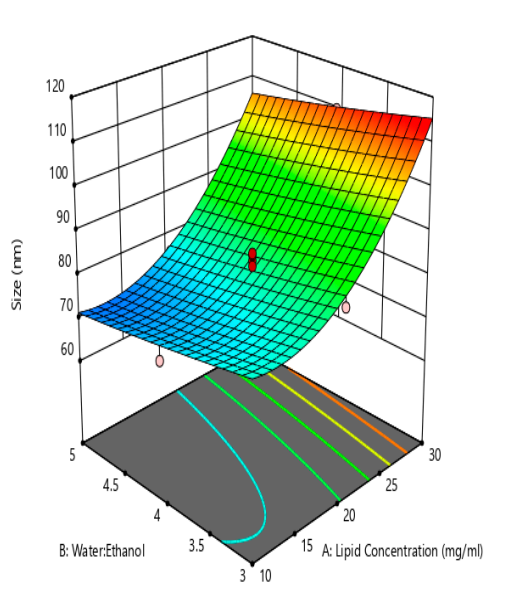

Design-Expert@ Software

Trial Version

Factor Coding: Actua

\section{Design- Expertô Software
Trial Version \\ Fadtor Coding: Atual}

\section{Size (nm)}

Design points above predicted value

O Design points below predicted value

$65 \square 113.56$

$X_{1}=$ A: Lipid Concentration

$x_{2}=c_{1}$ Prug concentration

Actual Factor

L.: WaterEEthanol = 4

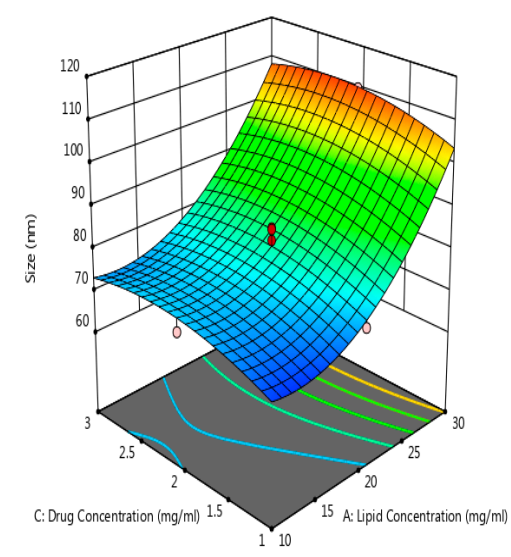

Figure 2. Cont. 

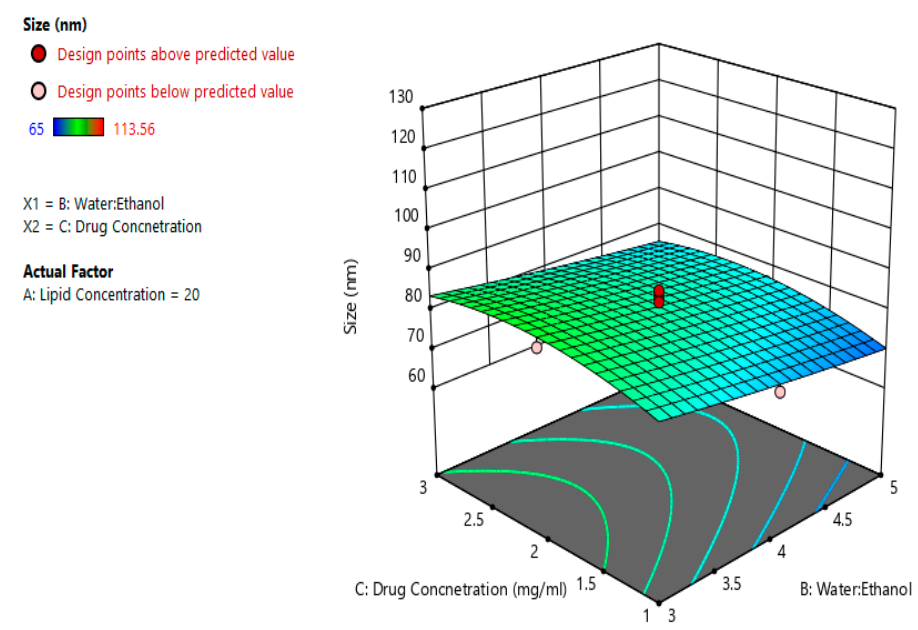

(c)
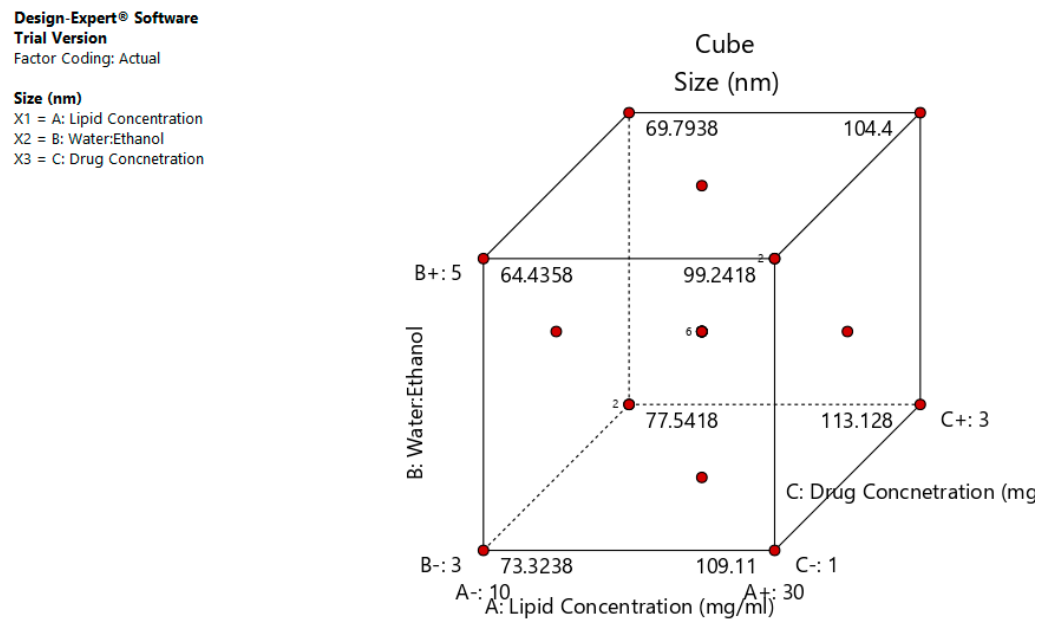

(d)

Figure 2. Effect of factors on the size of the dacarbazine liposomes (DL) (a) Effect of individual factors on Size; (b) Effect of combinations of two factors on Size (2D plots); (c) Effect of combinations of two factors on Size (3D plots); (d) Effect of all three factors on Size.

The entrapment efficiency of the drug should be constrained at maximum to make formulation and the whole process more cost-effective. On fitting the response data to various models, the data was best explained by the quadratic model (Table 5). Values of Model F-value, Lack of fit $F$-value and $p$-value are also favorable (Table 5).

Equation (6) represents the effect of independent variables on the entrapment efficiency of dacarbazine liposomes.

$$
\begin{aligned}
& \text { Entrapment Efficiency }=+25.55+3.13 \times \mathrm{A}-0.8070 \times \mathrm{B}+2.36 \times \mathrm{C}-3.89 \times \mathrm{AB}-1.41 \\
& \times \mathrm{AC}-0.7075 \times \mathrm{BC}-1.93 \times \mathrm{A}^{2}-0.7691 \times \mathrm{B}^{2}-0.7741 \times \mathrm{C}^{2}
\end{aligned}
$$

Values of entrapment efficiency ranged from $11.14 \%$ to $31.67 \%$. Same as size, the linear terms of lipid concentration and drug concentration have a positive effect on entrapment efficiency, whereas the linear term of this water:ethanol ratio has a negative effect. As evidenced by the values of the coefficients, the entrapment efficiency is most effected by the lipid concentration, followed by drug concentration and the water:ethanol ratio. As the lipid concentration increases, numerous and larger liposomes are formed, thus higher is the entrapment efficiency. Also, when the drug concentration is increased, more drug is entrapped in the liposomes. 
On the other hand, a greater water:ethanol ratio leads to smaller liposomes, which results in lesser drug entrapment. Figure $3 \mathrm{a}-\mathrm{d}$ illustrates the effect of factors on the entrapment efficiency of dacarbazine liposomes.

Design-Expert@ Software

\section{Trial Version}

Factor Coding: Actual

Entrapment Efficiency (\%)

- Design Points

- - $95 \% \mathrm{Cl}$ Bands

\section{Actual Factors}

A: Lipid Concentration $=20$

B: Water:Ethanol $=4$

C: Drug Concnetration $=2$
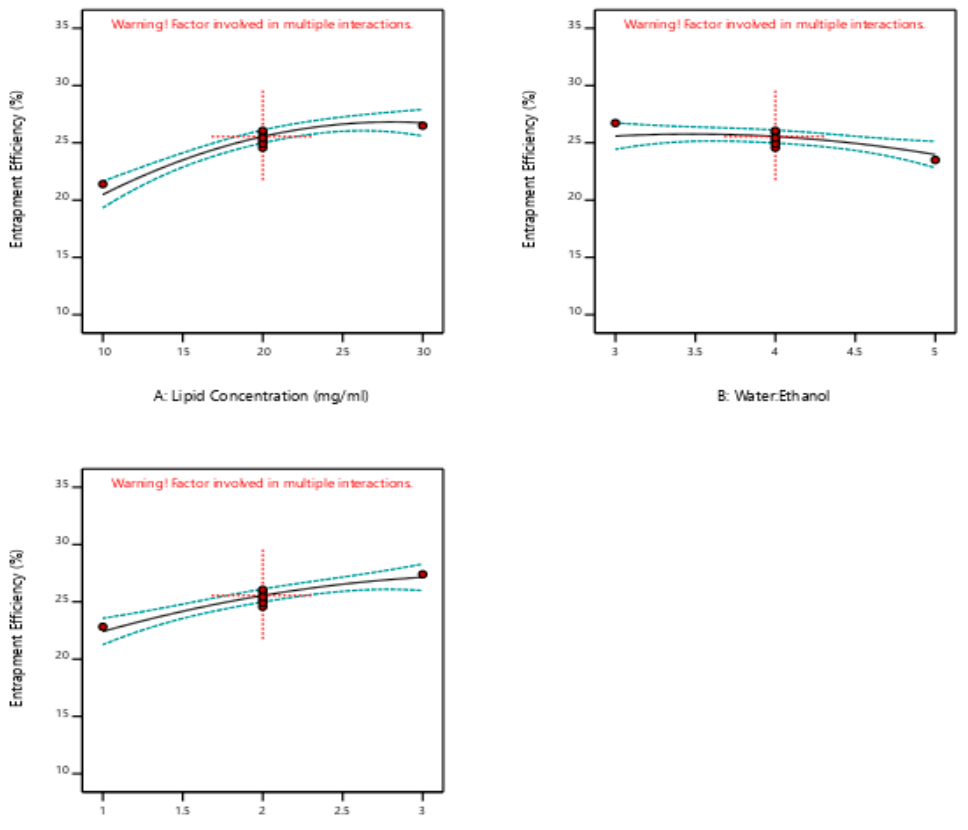

C: Drug Concnetration $(\mathrm{mg} / \mathrm{m}$ )

(a)

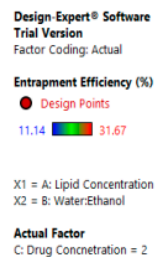

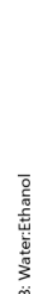

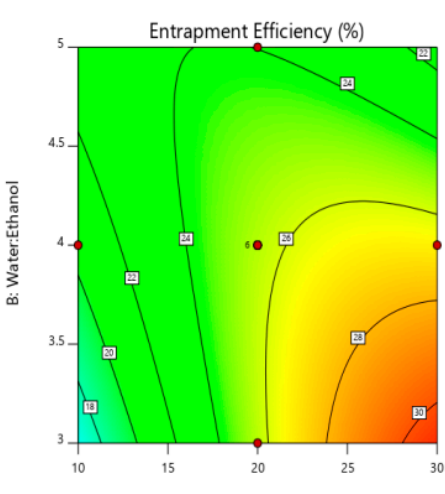

Trial Version
Factor Coding: Actual

Entrapment Efficiency (\%)
○ Design Points

$11.14 \square 31.67$

$X_{1}=A:$ : ipid Concentrataion
$X_{2}=C$ : Drug Concnetration

Actual Factor
B: Water:Ehanol $=4$

A: Lipid Concentration $(\mathrm{mg} / \mathrm{ml})$

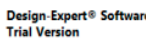

Trial Version
factor Coding: Actual

Entrapment Efficiency (x)

- Design points

$1.14 \square 31.67$

$x_{1}=8:$ Water:Ethanol
$x_{2}=C$ : Drug Concnetration

Actual Factor
A: Lipid Conce

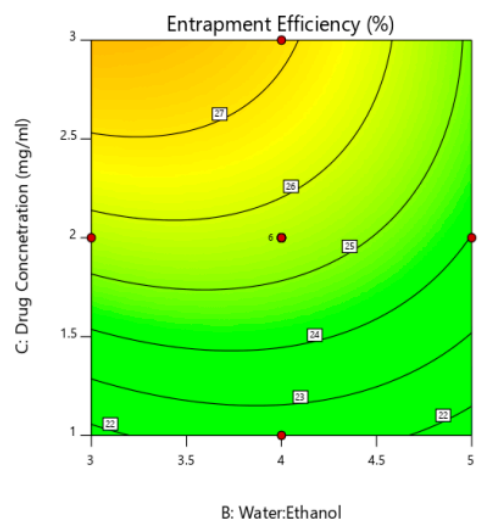

(b)

Figure 3. Cont.

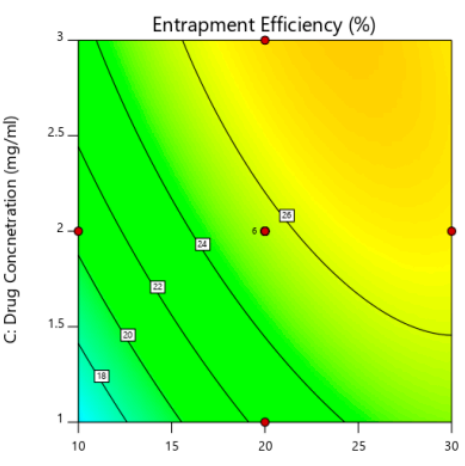

A: Lipid Concentration (mg/ml) 

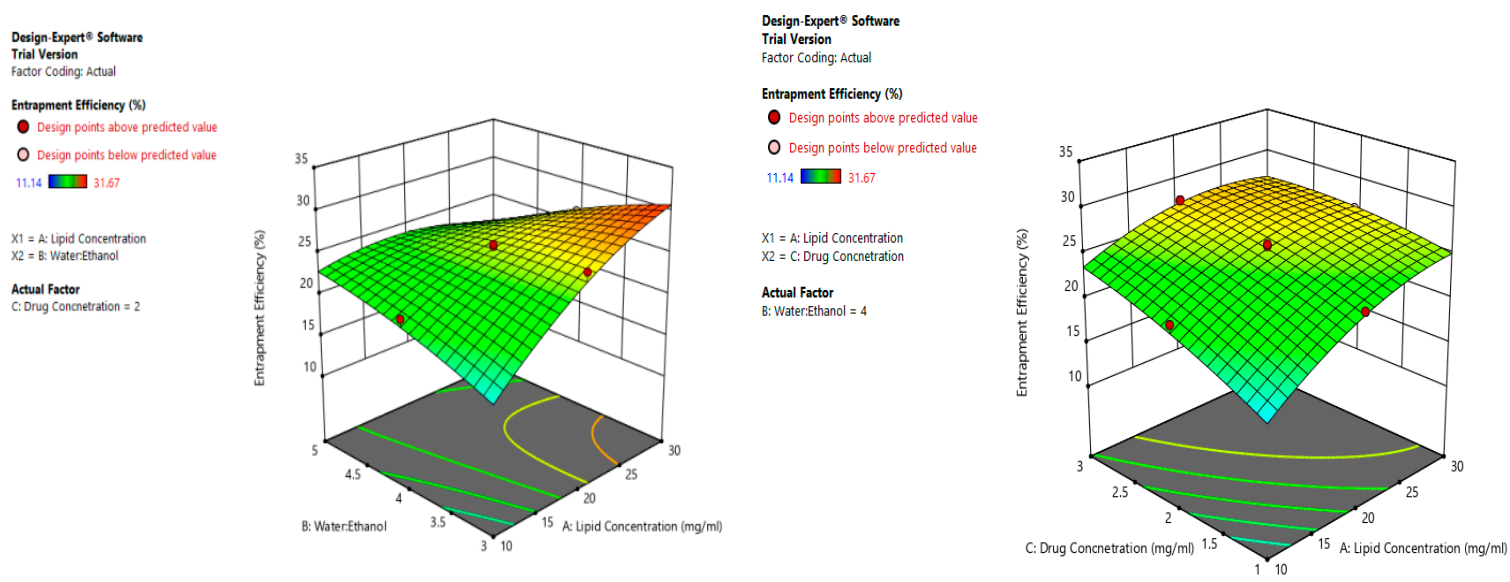

Design-Expert@ Software$$
\text { Factor Coding: Actual }
$$$$
\text { Entrapment Efficiency (\%) }
$$$$
\text { - Design points above predicted value }
$$$$
\text { Design points below predicted value }
$$$$
11.14 \square 31.67
$$

$\mathrm{X} 1=\mathrm{B}$ : Water:Ethanol $\mathrm{X} 2=\mathrm{C}:$ Drug Concnetration

Actual Factor A: Lipid Concentration $=20$

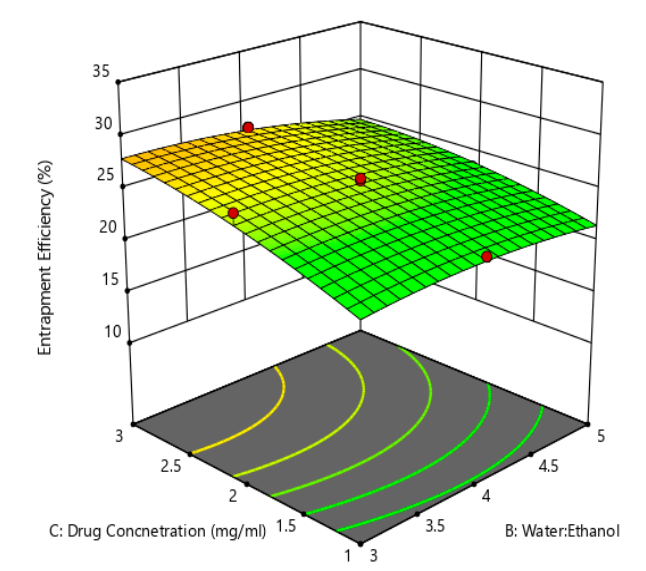

(c)

Design-Expert ${ }^{\circledR}$ Software Trial Version

Factor Coding: Actual

Entrapment Efficiency (\%)

$\mathrm{X} 1=\mathrm{B}$ : Water:Ethanol

X2 = C: Drug Concnetration

$\mathrm{X} 3=\mathrm{A}:$ Lipid Concentration

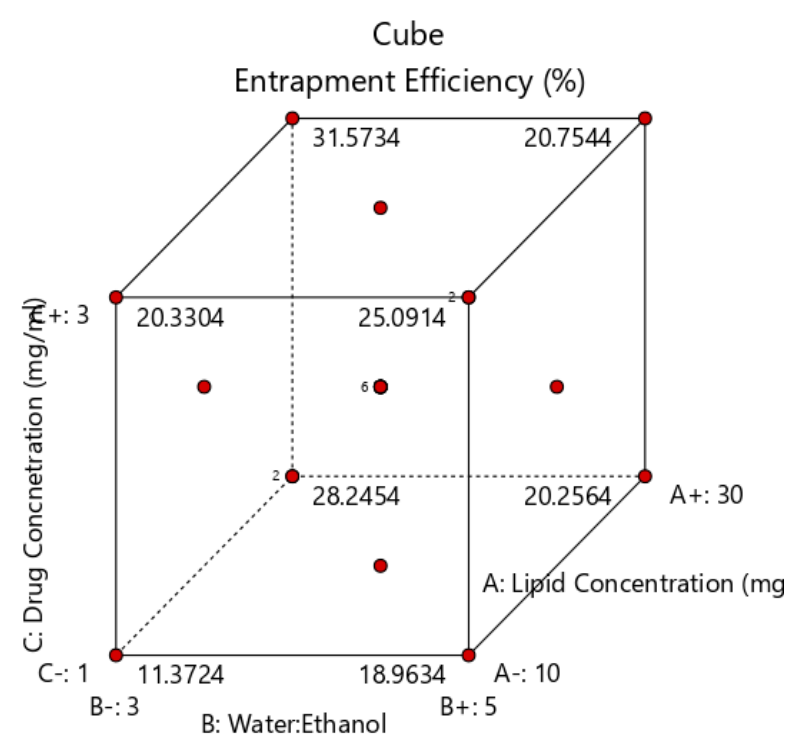

(d)

Figure 3. Effect of factors on entrapment efficiency of DL (a) Effect of individual factors on Entrapment Efficiency; (b) Effect of combinations of two factors on Entrapment Efficiency (2D plots); (c) Effect of combinations of two factors on Entrapment Efficiency (3D plots); (d) Effect of all three factors on Entrapment Efficiency. 


\section{Risk Assessment (First Level)}

Risk assessment is employed to identify and establish the effect of materials and process variables on the final characteristics of the formulation. In the given case, the effect of lipid concentration, water:ethanol ratio and drug concentration was assessed on the size and entrapment efficiency of the liposomes. The linear curve of predicted versus actual response, and the symmetrical distribution pattern in residual versus predicted and residual versus run graph for particle size and entrapment efficiency of the drug, suggested that the model applied was fit, and the chances of missing other variables that might affect CQAs of the final liposomes were low (Figure $4 a, b$ ).

Selection of Optimum Formulation

An optimum formulation of dacarbazine-loaded liposomes was identified through numerical optimization by setting the constraints on dependent variables, size (minimum), and entrapment efficiency (maximum). The software suggested 41 solutions, out of which the one with the highest desirability factor was selected. The selected formulation suggested $13.168 \mathrm{mg} / \mathrm{mL}$ of lipid concentration, five as water:ethanol ratio, and $3 \mathrm{mg} / \mathrm{mL}$ of drug concentration.

The predicted size of the optimized formulation was $69.093 \mathrm{~nm}$, and the obtained size was $74.66 \mathrm{~nm}$; the predicted entrapment efficiency of the optimized formulation was $25.436 \%$, while the obtained entrapment efficiency was $24.19 \%$. Therefore, it can be seen that the predicted and obtained values are near.

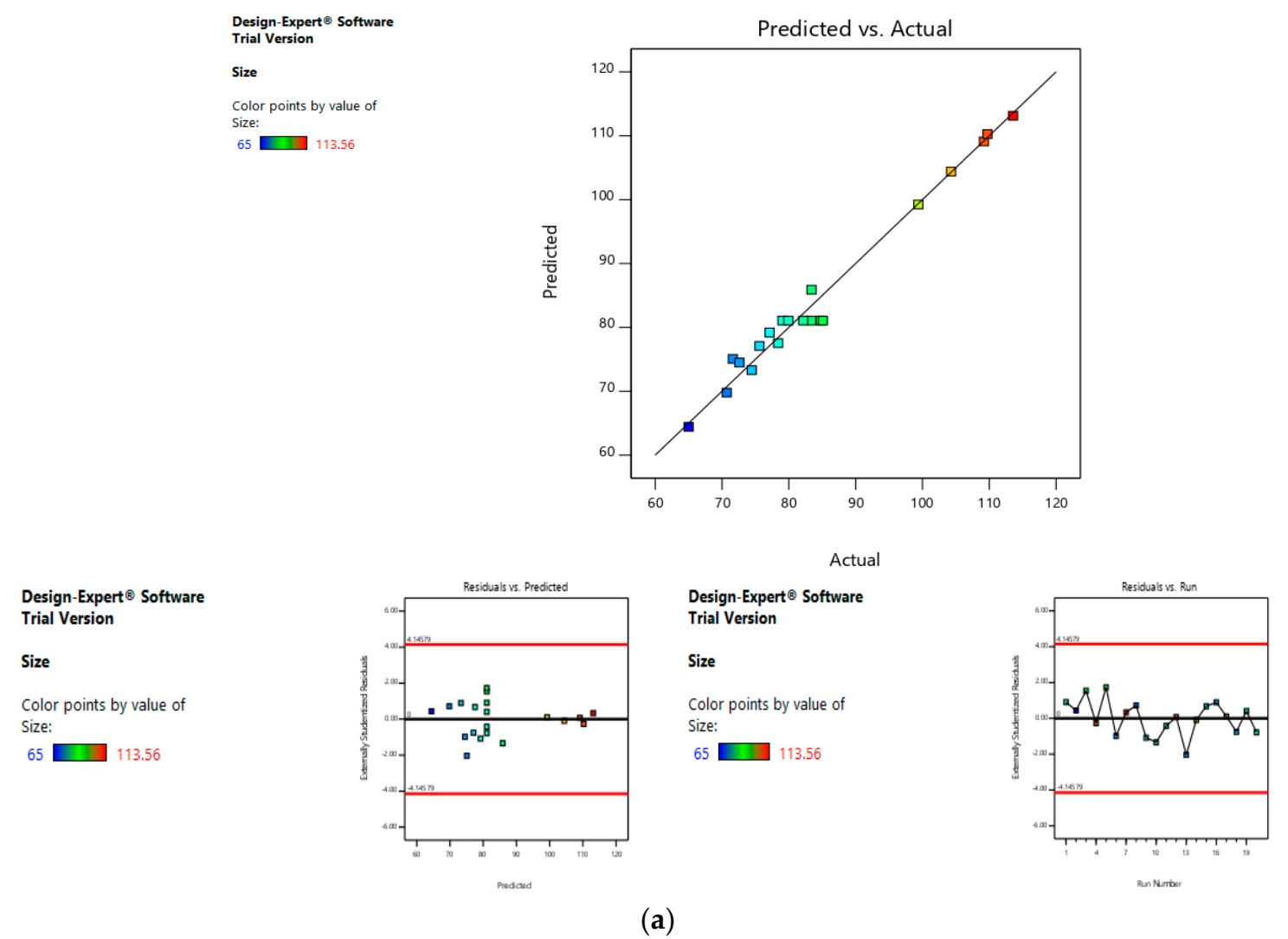

Figure 4. Cont. 

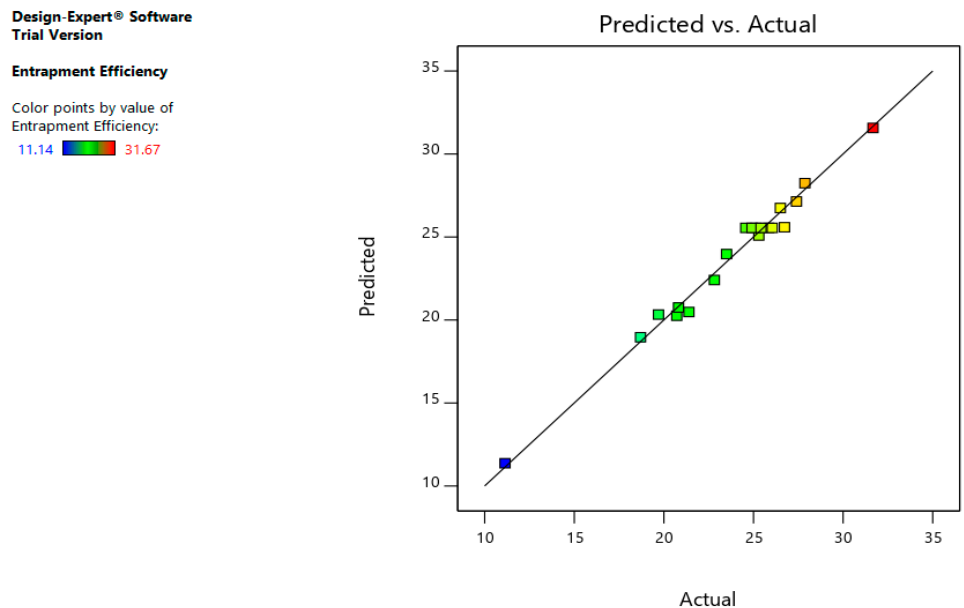

Design-Expert ${ }^{\circledR}$ Software Trial Version

Entrapment Efficiency

Color points by value of Entrapment Efficiency:

$11.14 \square 31.67$

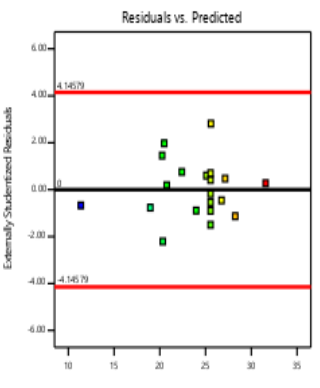

Design-Expert ${ }^{\circledR}$ Software Trial Version

Entrapment Efficiency

Color points by value of

Entrapment Efficiency:

$11.14 \square$
$\square$

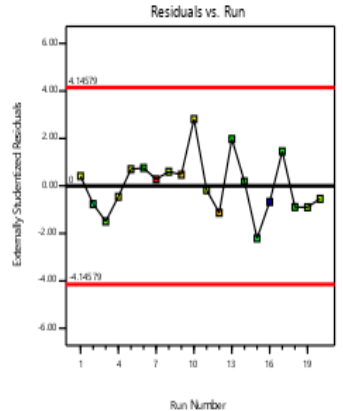

(b)

Figure 4. Risk assessment (first level) (a) with respect to size. (b) with respect to entrapment efficiency.

\subsubsection{Second Level}

For the second level, the optimum values of lipid concentration $(13.168 \mathrm{mg} / \mathrm{mL})$ and water:ethanol ratio (5) were already known from the results of the first level. Here, the two independent variables' dacarbazine concentration and eugenol concentration were optimized. The dependent variables were the size and ratio of entrapped eugenol to entrapped dacarbazine. The size was constrained at a minimum. The $r$, the ratio of entrapped eugenol to entrapped dacarbazine, was constrained at maximum. It is because dacarbazine is a very potent anti-cancer drug, having a very low anti-cancer dose $(2-4.5 \mathrm{mg} / \mathrm{kg})$, while eugenol is an herbal agent with a high anti-cancer dose as compared to dacarbazine; researchers have introduced $100-125 \mathrm{mg} / \mathrm{kg}$ of eugenol in melanoma-bearing mice to observe anti-melanoma effects [34]. Therefore, since both the drugs are to be entrapped in the same formulation, the ratio of entrapped eugenol to entrapped dacarbazine should be as high as possible, so that maximum amount of eugenol is administered when the anti-cancer dose of dacarbazine is given to the animals (through liposomes).

When the minimum and maximum values of independent variables were put into the CCD statistical experimental design, the software suggested 13 runs with five center points. The formulations were made, analyzed, and the values of the dependent variables were put into the table (Table 6). Same as the first level, polynomial equations were generated to predict the effect of individual factors and combinations of factors on dependent variables. 
Table 6. Response data analysis (Second level). Values of Response 1 and Response 2 for 13 different combinations of Factor 1 and Factor 2.

\begin{tabular}{ccccc}
\hline Run & Factor 1 & Factor 2 & Response 1 & Response 2 \\
\hline $\begin{array}{c}\text { Dacarbazine } \\
\text { Concentration } \\
(\mathbf{m g} / \mathbf{m L})\end{array}$ & $\begin{array}{c}\text { Eugenol } \\
\text { Concentration } \\
(\mathbf{m g} / \mathbf{m L})\end{array}$ & Size (nm) & Eugenol:Dacarbazine \\
\hline 1 & 3 & 5 & $125.64 \pm 3.63$ & $1.5 \pm 0.17$ \\
2 & 2 & 5 & $112.6 \pm 4.7$ & $1.95 \pm 0.13$ \\
3 & 2 & 7.5 & $139.48 \pm 3.23$ & $2.38 \pm 0.2$ \\
4 & 1 & 5 & $100.28 \pm 2.74$ & $2.36 \pm 0.17$ \\
5 & 1 & 10 & $156.82 \pm 5.13$ & $3.24 \pm 0.21$ \\
6 & 3 & 7.5 & $153.9 \pm 4.85$ & $1.82 \pm 0.11$ \\
7 & 3 & 70 & $178.81 \pm 6.72$ & $1.9 \pm 0.08$ \\
8 & 2 & 7.5 & $141.74 \pm 2.74$ & $2.24 \pm 0.18$ \\
9 & 2 & 10 & $160.35 \pm 4.27$ & $2.35 \pm 0.15$ \\
10 & 2 & 7.5 & $140.73 \pm 2.2$ & $2.4 \pm 0.14$ \\
11 & 2 & 7.5 & $124.66 \pm 4.28$ & $2.19 \pm 0.14$ \\
12 & 1 & 7.5 & $144.57 \pm 3.5$ & $3.06 \pm 0.24$ \\
13 & 2 & & & $2.22 \pm 0.15$ \\
\hline
\end{tabular}

Response Analysis for Optimization

On fitting the response values to various models, the data were best explained by the linear model (Table 2). Values of Model $F$-value, Lack of fit $F$-value and $p$-value were also favorable (Table 2).

Equation (7) represents the effect of independent variables on the size of the final liposomes.

$$
\text { Size }=+140.34+12.76 \mathrm{~A}+26.99 \mathrm{~B}
$$

The mean size ranged from $100.28 \mathrm{~nm}$ to $178.81 \mathrm{~nm}$. The equation suggests that the size of the liposomes is more influenced by eugenol concentration. The linear terms of dacarbazine concentration and eugenol concentration both have a positive effect on the size of the liposomes. Thus, the size of the liposomes increases with an increase in any of the drug concentration. Figure $5 \mathrm{a}-\mathrm{c}$ represents the effect of independent variables on the size of dual drugs-loaded liposomes.

Design-Expert ${ }^{\circledR}$ Software

Trial Version

Factor Coding: Actual

$$
\begin{aligned}
& \text { Size (nm) } \\
& \text { Design Points } \\
& --95 \% \mathrm{Cl} \text { Bands }
\end{aligned}
$$

\section{Actual Factors}

A: Dacarbazine Concentration $=1.5$

B: Eugenol Concentration $=7.5$
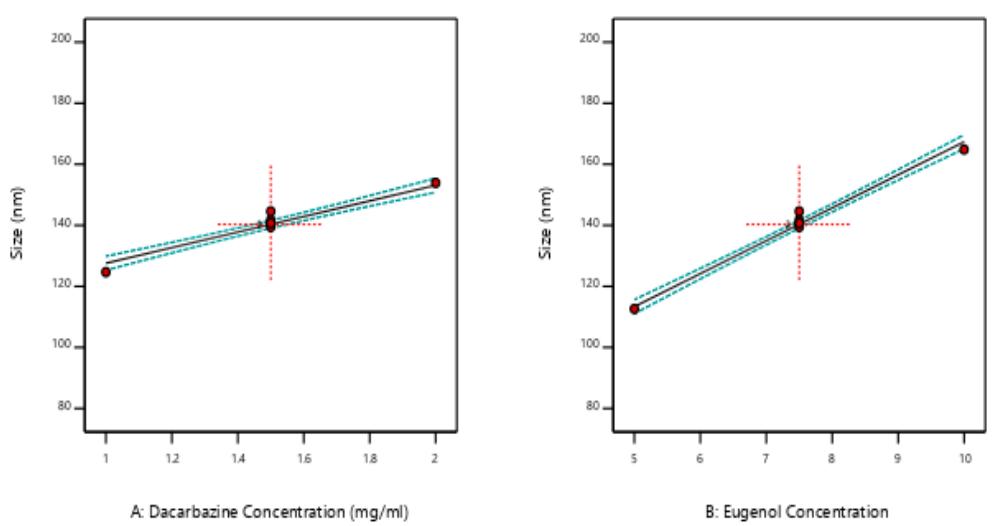

(a)

Figure 5. Cont. 


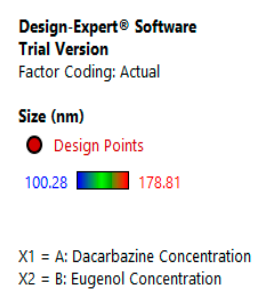

$\mathrm{X} 2=\mathrm{B}$ : Eugenol Concentration

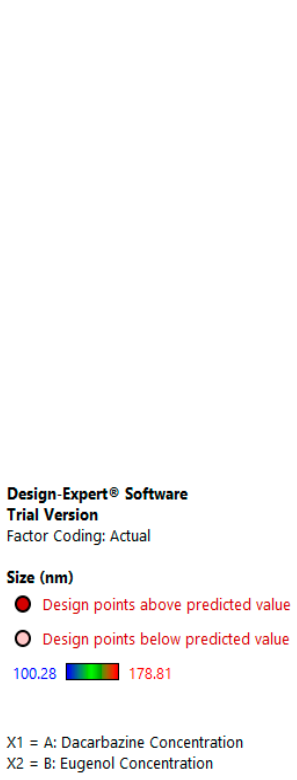

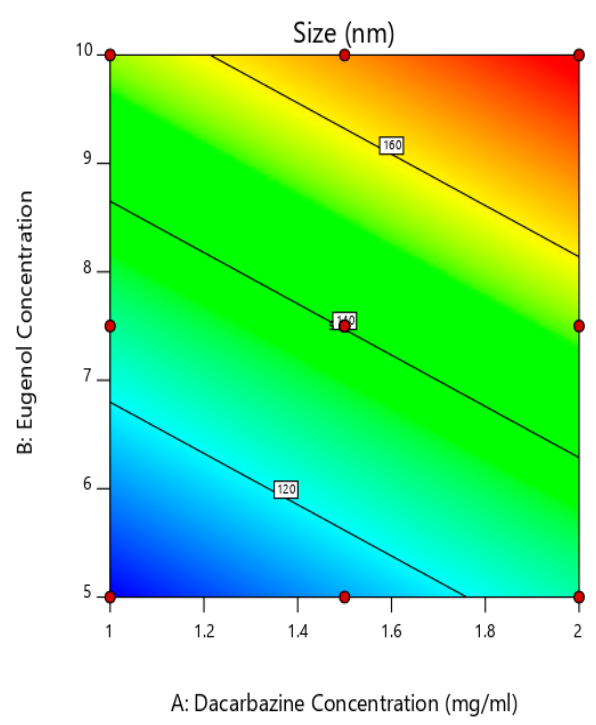

(b)

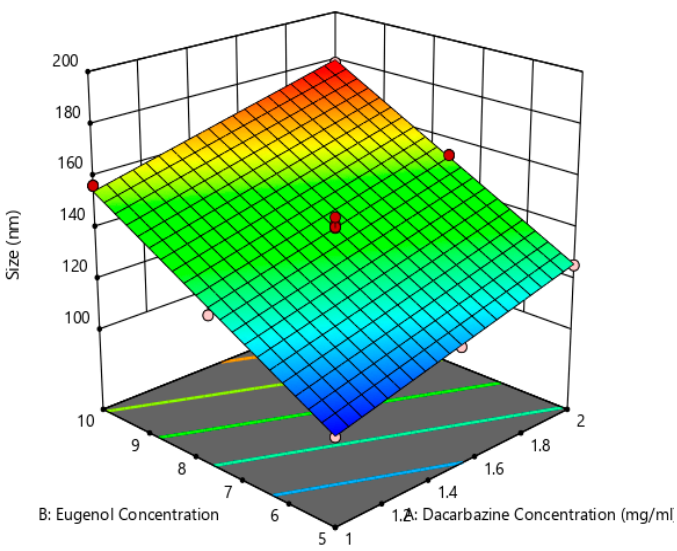

(c)

Figure 5. Effect of factors on size of DEL (a) Effect of individual factors on the size of dual loaded liposomes; (b) Effect of the combination of two factors on the size of dual loaded liposomes (2D plot); (c) Effect of the combination of two factors on the size of dual loaded liposomes (3D plot).

Eugenol:Dacarbazine was constrained at maximum. On fitting the response values to various models, the data was best explained with the quadratic model (Table 2). Values of Model F-value, Lack of fit $F$-value and $p$-value were also favorable (Table 2).

Equation (8) represents the effect of independent variables on the size of the final liposomes.

$$
\text { Eugenol:Dacarbazine }=+2.29-0.5733 \mathrm{~A}+0.2883 \mathrm{~B}-0.1200 \mathrm{AB}+0.1210 \mathrm{~A}^{2}-0.1440 \mathrm{~B}^{2}
$$

Values of the ratio of entrapped eugenol to entrapped dacarbazine range between 1.5 and 3.24. As suggested by the equation, the linear term of dacarbazine concentration has a negative effect, and the linear term of eugenol concentration has a positive effect on entrapped eugenol:dacarbazine; while dacarbazine concentration has a more pronounced effect. Figure $6 a-c$ represents the effect of independent variables on the entrapped Eugenol:Dacarbazine ratio of dual drugs-loaded liposomes. 
Design-Expert ${ }^{\circledR}$ Software

\section{Trial Version}

Factor Coding: Actual

\section{Eugenol:Dacarbazine}

O Design Points

- - $95 \% \mathrm{Cl}$ Bands

\section{Actual Factors}

A: Dacarbazine Concentration $=1.5$

B: Eugenol Concentration $=7.5$
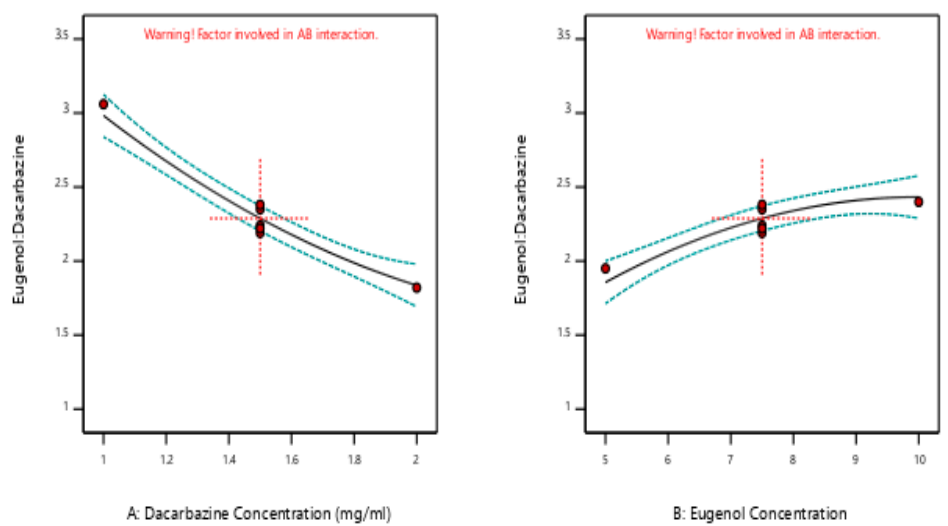

(a)

\section{Design-Expert@ Software \\ Trial Version
Factor Coding: Actual \\ Eugenol:Dacarbazine \\ O Design Points \\ $1.5 \square 3.24$}

$\mathrm{X} 1=\mathrm{A}:$ Dacarbazine Concentration $X_{2}=B:$ Eugenol Concentration

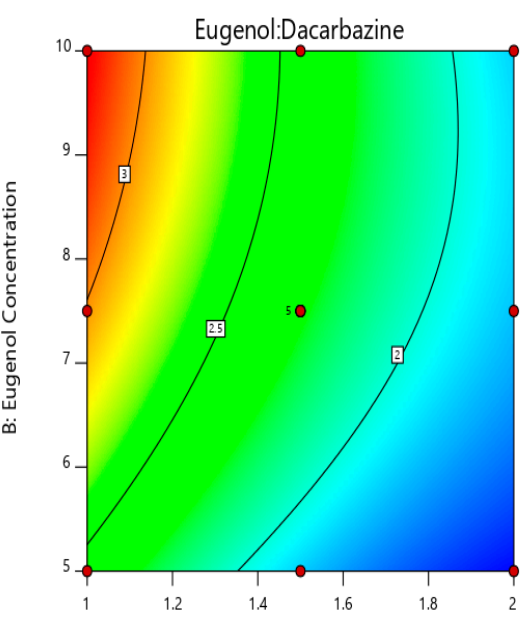

A: Dacarbazine Concentration ( $\mathrm{mg} / \mathrm{ml})$

(b)
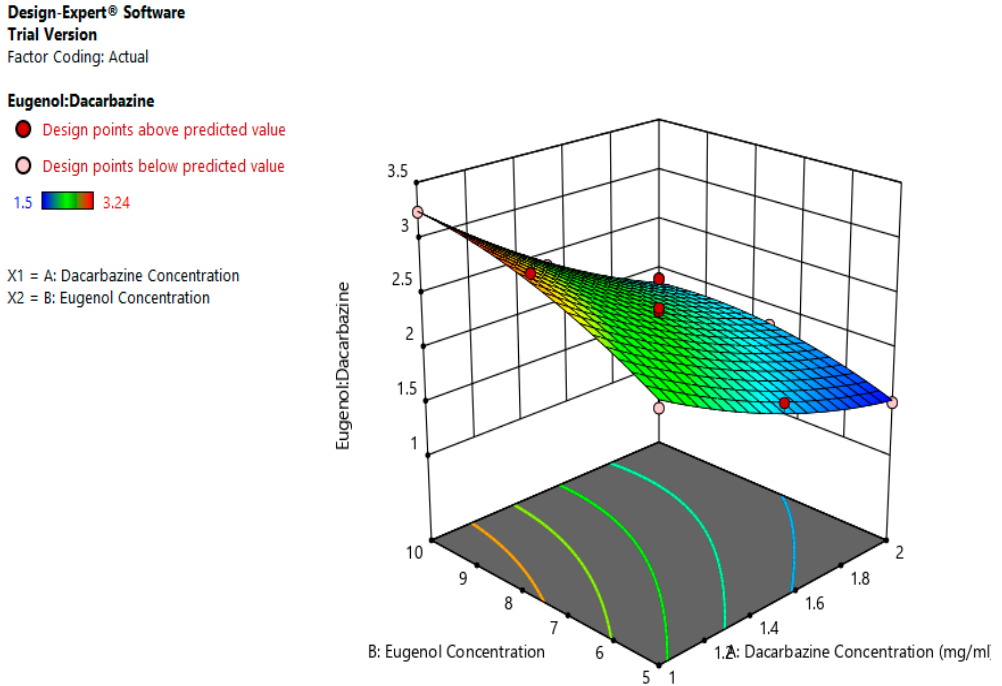

(c)

Figure 6. Effect of factors on Eugenol:Dacarbazine ratio of DEL (a) Effect of individual factors on Eugenol: Dacarbazine ratio of dual loaded liposomes; (b) Effect of combination of two factors on Eugenol: Dacarbazine ratio of dual loaded liposomes (2D plot); (c) Effect of Effect of combination of two factors on Eugenol:Dacarbazine ratio of dual loaded liposomes (3D plot). 


\section{Risk Assessment (Second Level)}

In the second level of $\mathrm{QbD}$, the effect of dacarbazine concentration and eugenol concentration was assessed on the size and entrapment efficiency of the liposomes. The linear curve of predicted versus actual response, and symmetrical distribution pattern in residual versus predicted, and residual versus run graph for particle size and eugenol:dacarbazine, suggested that the model applied was fit, and the chances of missing other variables that might affect CQAs of the final liposomes were low (Figure 7a,b).

\section{Selection of Optimum Formulation}

Optimum formulation of dual-loaded liposomes was identified through a numerical optimization by setting the constraints on dependent variables, size (minimum), and eugenol:dacarbazine (maximum). The software suggested 15 solutions, out of which the one with the highest desirability factor was selected. The selected formulation suggested $1 \mathrm{mg} / \mathrm{mL}$ of dacarbazine concentration, and $6.882 \mathrm{mg} / \mathrm{mL}$ of eugenol concentration. The predicted size of the DEL synthesized by the suggested formula was $120.889 \mathrm{~nm}$, and the size obtained was $124.0 \mathrm{~nm}$. The predicted eugenol:dacarbazine value was 2.873 , while it was practically observed to be 2.906 . So, the predicted and obtained values were found to be in agreement.
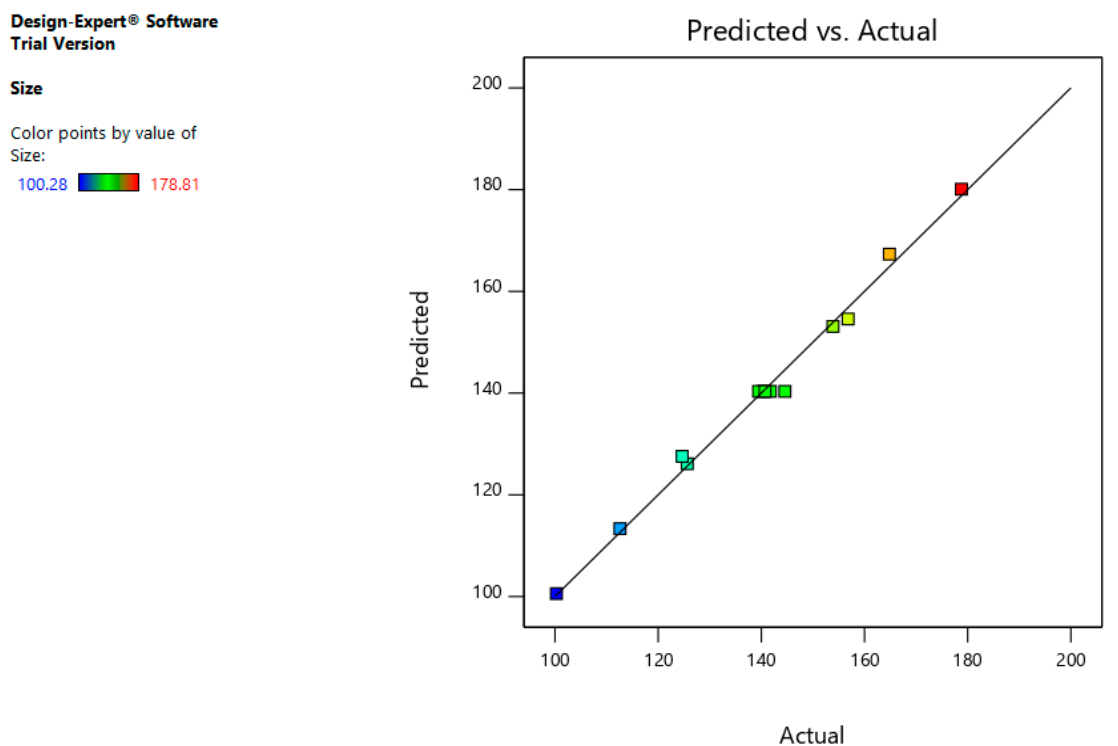

Design-Expert ${ }^{\circledR}$ Software Trial Version

Size

Color points by value of Size:

100,28

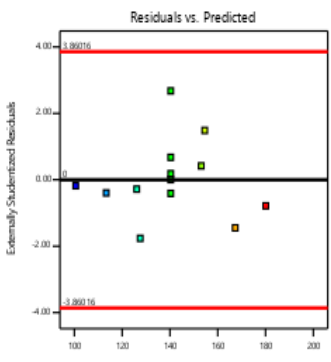

Design-Expert ${ }^{\circledR}$ Software Trial Version

Size

Color points by value of

Size:

$100.28 \square 178.8$

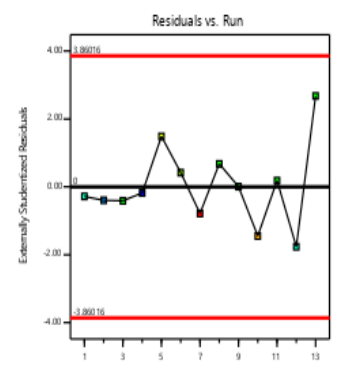

(a)

Figure 7. Cont. 


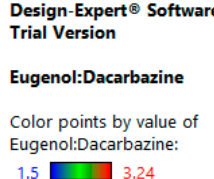

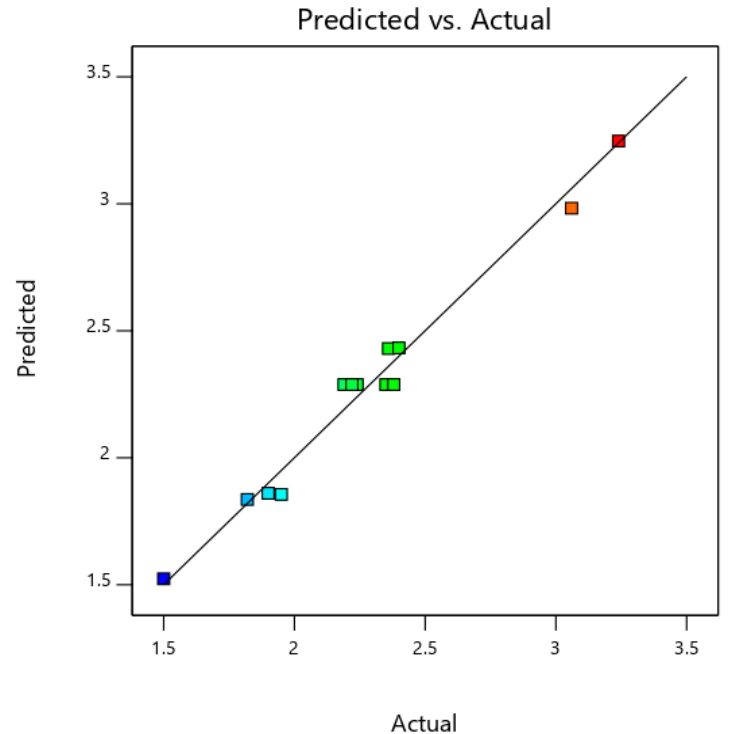

Design-Expert ${ }^{2}$ Software Trial Version

Eugenol:Dacarbazine

Color points by value of Eugenol:Dacarbazine:

$1.5 \square 3.24$

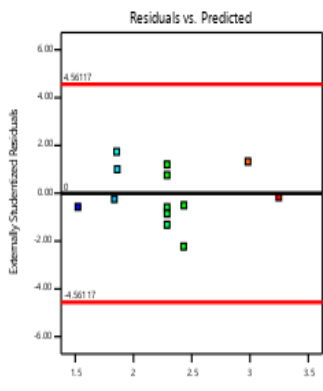

Design-Expert $₫$ Software Trial Version

Eugenol:Dacarbazine

Color points by value of Eugenol:Dacarbazine:

$1.5 \square 3.24$
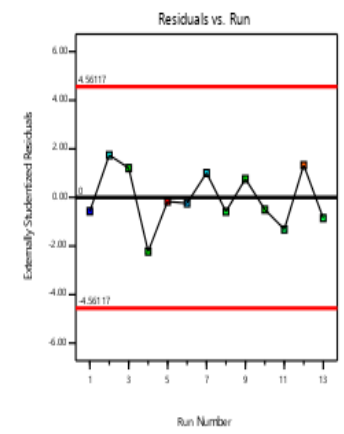

(b)

Figure 7. Risk assessment (second level) (a) with respect to size. (b) with respect to Eugenol:Dacarbazine.

\subsection{Surface Functionalization of Optimized Formulation}

Different concentrations of HA solution were used to coat the optimized cationic liposomes, and the size of the final coated liposomes was assessed in each case to determine the optimum concentration of HA solution to be used. With $0.005 \%$ solution, only a negligible increase in size was observed. When $0.01 \%$ HA solution was used, the size of the liposomes increased from $124.0 \mathrm{~nm}$ to $159.5 \mathrm{~nm}$. With $0.05 \%$ and $0.1 \%$ HA solutions, the size increased to $235.7 \mathrm{~nm}$ and $364.1 \mathrm{~nm}$, respectively. Since the increase in size was too large, these two concentrations were discarded. Increase in size with $0.005 \%$ HA solution was too less to indicate any significant coating. Hence, $0.01 \%$ concentration was selected as the optimum concentration of HA solution. The liposomes coated with $0.01 \%$ HA solution were later analyzed by TEM and SEM to visualize and confirm a significant coating of HA.

\subsection{Particle Size, Size Distribution}

Blank liposomes had a size of $54.00 \pm 1.73 \mathrm{~nm}$, which increased to $74.66 \pm 2.71 \mathrm{~nm}$ when dacarbazine was loaded. When both the drugs were loaded, the size further increased to $124.00 \pm 4.26 \mathrm{~nm}$. After surface functionalization of the optimized dual loaded liposomes, the size remarkably increased to $159.5 \pm 3.62 \mathrm{~nm}$. This is the reason that every effort was made from the beginning to achieve the minimum size at every step. PDI, which is a measure of the size distribution of the nanoparticles, was within a suitable range for all the formulations. 


\subsection{Zeta Potential}

As the zeta potential is one of the major determinants of the stability of the nanoformulations, it too was determined. Zeta potential of BL was found to be $-9.97 \mathrm{mV}$, which indicates a moderate stability of the liposomes. The zeta potential of DEL was found to be -8.70 , which is nearly the same as that of the blank liposomes. Since both the drugs are entrapped inside the liposomes, the surface charge remains more or less unaltered.

After coating of liposomes with HA (DELC), the zeta potential was -12.8. Here, the negative charge is supposed to be due to the carboxylic groups of HA present on the surface of the liposomes. This increase in the negative charge of the liposomes indicates towards a successful coating of the liposomes with the electronegative HA.

\subsection{Electron Microscopy}

Figure 8 shows the TEM images of (a) BL, (b) DEL, and (c) DELC. As it can be seen in the images, the blank liposomes are hollow structures bounded by a thin lipid bilayer. However, the DEL have drug entrapped in the core, as well as in the lipid bilayer, which is evident by the thickening of the bilayer. In the image of the DELC, the surface of the liposomes is irregular which confirms the coating of liposomes by HA.

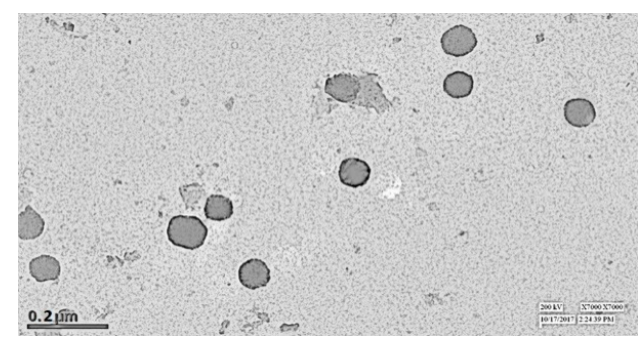

(a)

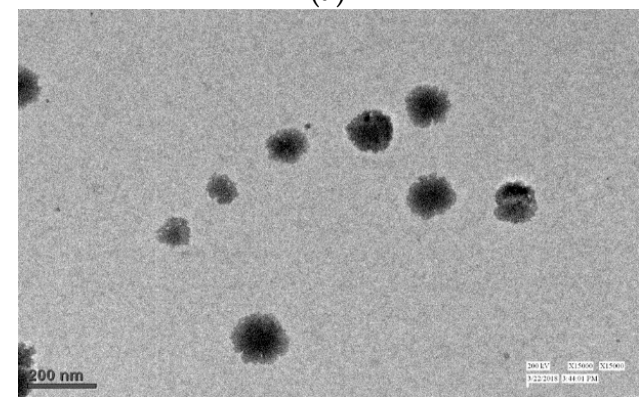

(b)

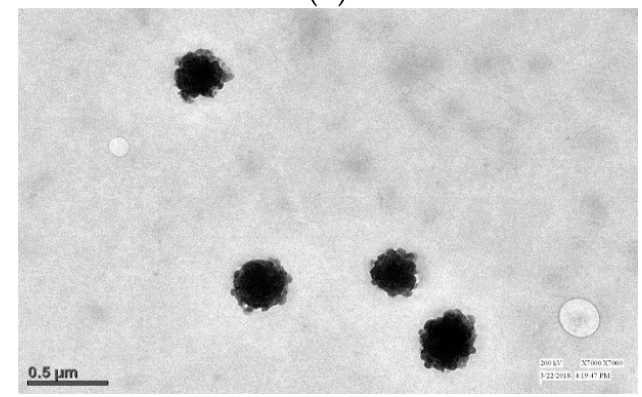

(c)

Figure 8. Transmission Electron Microscopy (TEM) images of (a) Blank Liposomes (b) Dacarbazine and Eugenol Liposomes (c) Dual loaded surface-functionalized liposomes. (a) Liposomes appear hollow with thin lipid bimembrane (b) Liposomes have darker core and thickened lipid bimembrane indicating towards loading of both drugs (c) Liposomes have irregular surface indicating surface coating. 
Figure 9 shows the SEM images of (a) BL, (b) DEL, and (c) DELC. SEM images are also in agreement with the TEM images, showing a somewhat smaller and regular structure of blank liposomes, bigger structures of DEL, and bigger with the irregular surface of DELC. The sizes revealed by TEM and SEM analysis are also in agreement with the results of particle size analysis by zeta sizer. Also, SEM and TEM images revealed no aggregation of the liposomal structures.

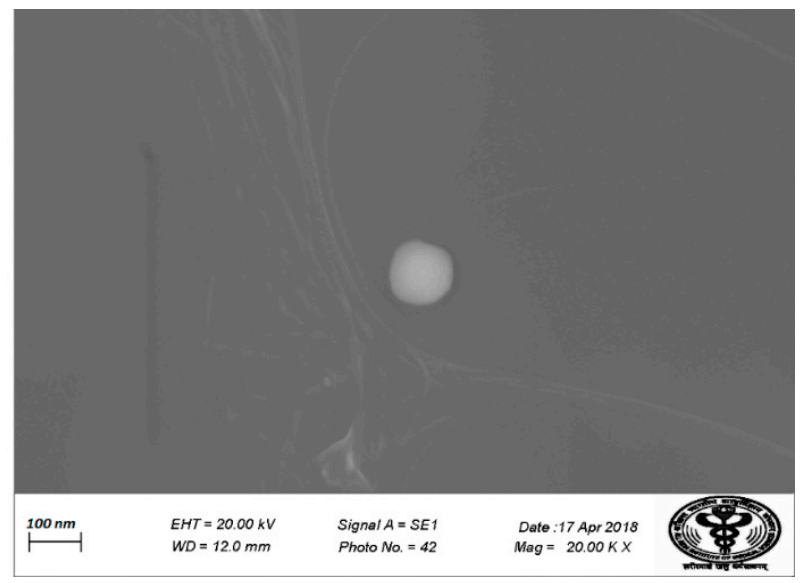

(a)

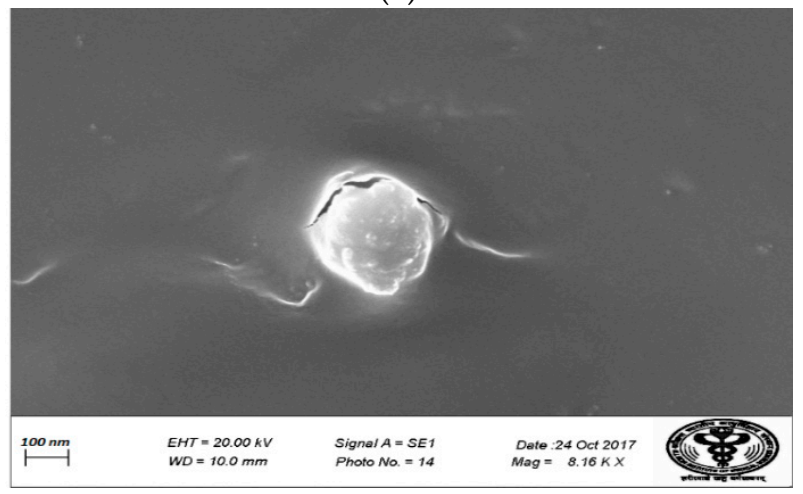

(b)

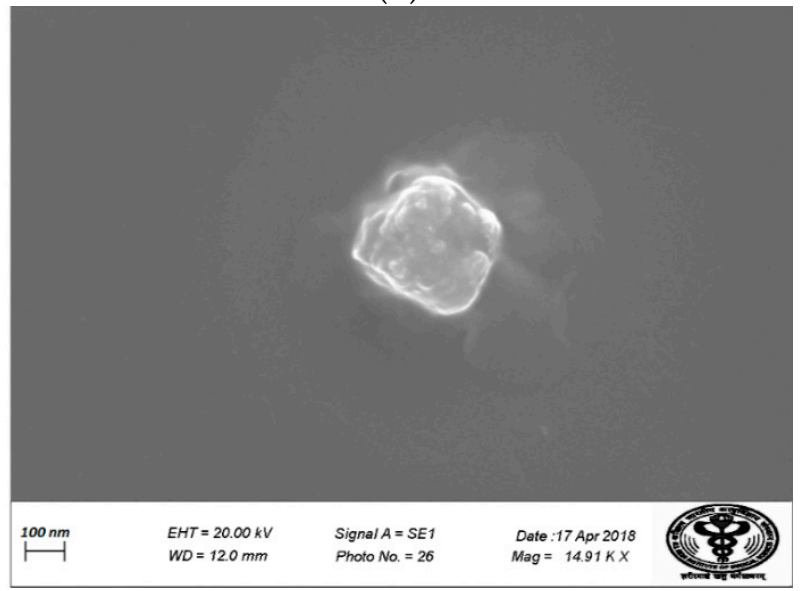

(c)

Figure 9. Scanning Electron Microscopy (SEM) images of (a) Blank Liposomes; (b) Dacarbazine and Eugenol Liposomes; (c) Dual loaded surface-functionalized liposomes. (a) More spherical and round liposomes (b) Liposomes are bigger in size (c) Surface of liposomes appear irregular due to surface coating. 


\subsection{Drug Loading}

The absorbance of the ethanolic solution of drugs-loaded liposomes was measured at $\lambda_{1}{ }^{\text {et }}$ and $\lambda_{2}{ }^{\text {et }}$, and substituted into Equations (1) and (2) which were then solved to find out the values of $C_{d}{ }^{\text {et }}$ and $\mathrm{C}_{\mathrm{e}}{ }^{\text {et }}$. After multiplying these values with the dilution factor, the concentration of dacarbazine was found to be $4.374 \mathrm{mg}$, and the concentration of eugenol was found to be $12.714 \mathrm{mg}$ in the liposomes. Calculating the percentages, the Dacarbazine loading was found to be $15.272 \%$, and Eugenol loading was found to be $44.392 \%$.

\subsection{Entrapment Efficiency}

Since the amount of dacarbazine initially added was $25 \mathrm{mg}(1 \mathrm{mg} / \mathrm{mL}$ in $25 \mathrm{~mL}$ water), and the amount entrapped was $4.374 \mathrm{mg}$, the entrapment efficiency of dacarbazine was $17.49 \%$.

The amount of Eugenol initially added was $34.41 \mathrm{mg}(6.882 \mathrm{mg} / \mathrm{mL}$ in $5 \mathrm{~mL}$ ethanol), and the amount entrapped was $12.714 \mathrm{mg}$, so the entrapment efficiency of eugenol was $36.94 \%$.

\subsection{Drug Release}

Absorbance $\left(A_{1}\right.$ and $\left.A_{2}\right)$ of aliquots of release media withdrawn at different time points were measured at $\lambda_{1}$ and $\lambda_{2}$ against pure release media as blank. The amount of drugs present (cumulative amount of drugs released) in the release media at different time intervals was calculated by putting these absorbance values in Equations (3) and (4). Release rates of drugs were determined for both uncoated (DEL) and HA-coated (DELC) liposomes. Plots were made between the time interval and cumulative percent of drug released from DEL (Figure 10) and DELC (Figure 11). As can be seen from the plots, the release of drugs was more sustained from DELC, indicating the role of HA-coating in slowing down the release of drugs. From DEL, in 12 h, $63.6 \pm 2.04 \%$ of dacarbazine and $77.36 \pm 2.74 \%$ of eugenol was released, while from DELC, only $44.24 \pm 2.55 \%$ of dacarbazine and $68.62 \pm 3.20 \%$ of eugenol was released in $12 \mathrm{~h}$. In $24 \mathrm{~h}$, the cumulative released amount was found to be $78.46 \pm 4.7 \%$ of dacarbazine and $89.21 \pm 3.64 \%$ of eugenol from DEL, and $61.78 \pm 3.74 \%$ of dacarbazine and $81.73 \pm 2.10 \%$ of eugenol from DELC. $98.36 \pm 1.21 \%$ dacarbazine and $99.73 \pm 0.18 \%$ eugenol were released in a span of $72 \mathrm{~h}$ from DEL. $84.67 \pm 2.64 \%$ dacarbazine and $97.1 \pm 1.78 \%$ eugenol were released from DELC in $72 \mathrm{~h}$. Thus, the release of both of the drugs from DEL and DELC was found to be sustained, but DELC showed more sustained drugs release, owing to HA-coating on the surface.

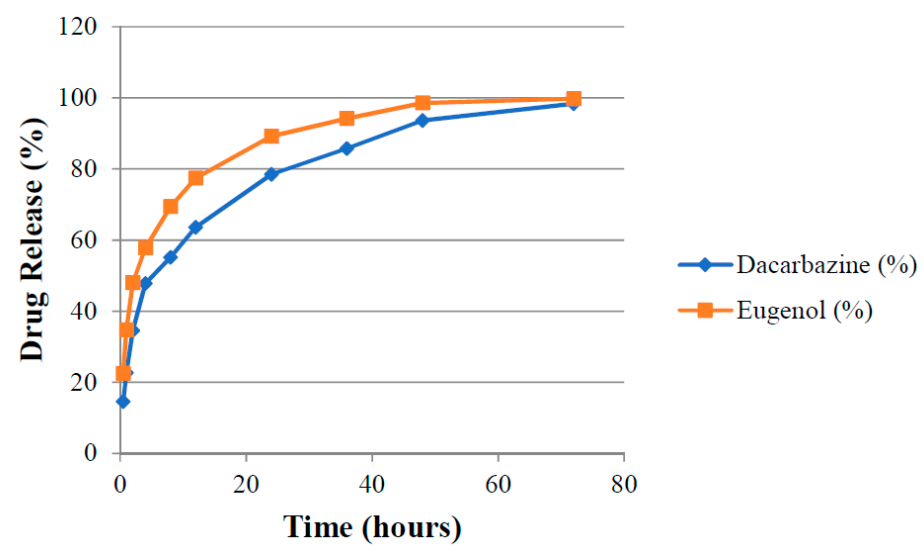

Figure 10. Cumulative release of Dacarbazine and Eugenol from uncoated liposomes. 


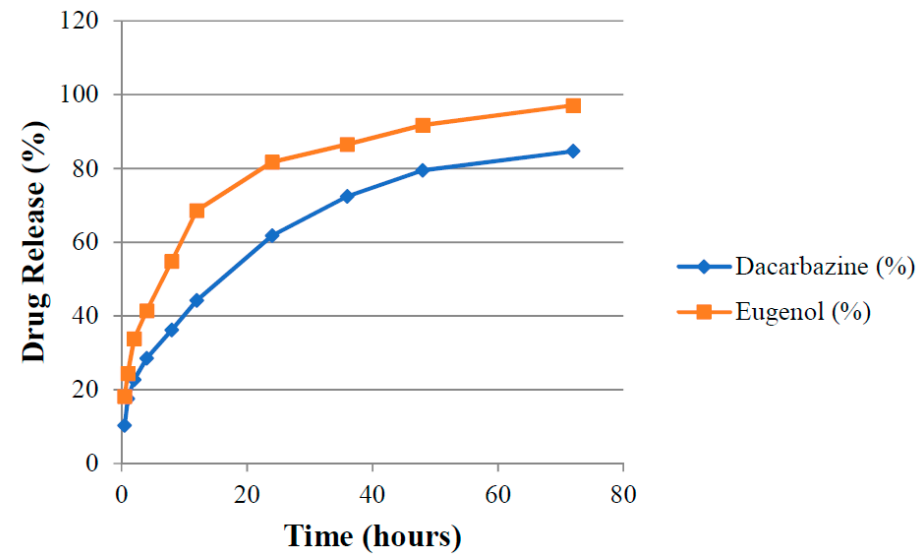

Figure 11. Cumulative release of Dacarbazine and Eugenol from hyaluronic acid (HA)-coated liposomes.

\subsection{Stability Study}

The size, PDI and drug content of lyophilized liposomal formulation were studied for four weeks, and results are summarized in Table 7. Liposomes were found to be fairly stable as they did not show any remarkable increase in size or PDI; neither had they shown a significant reduction in their drug content. This implies that, in the lyophilized form and under suitable storage conditions, formulated liposomes were able to retain their size without any leakage or leeching of drugs.

Table 7. Storage Stability.

\begin{tabular}{|c|c|c|c|c|c|c|}
\hline \multicolumn{2}{|c|}{ Stability Parameters } & 0 Weeks & 1 Weeks & 2 Weeks & 3 Weeks & 4 Weeks \\
\hline \multicolumn{2}{|c|}{ Size (nm) } & $124.0 \pm 3.62$ & $126.47 \pm 2.16$ & $131.8 \pm 4.26$ & $138.13 \pm 6.1$ & $147.94 \pm 6.73$ \\
\hline \multicolumn{2}{|c|}{ poly dispersity index (PDI) } & $0.214 \pm 0.062$ & $0.238 \pm 0.040$ & $0.277 \pm 0.086$ & $0.304 \pm 0.081$ & $0.316 \pm 0.094$ \\
\hline \multirow{2}{*}{$\begin{array}{c}\text { Drug } \\
\text { Content }(\%)\end{array}$} & Dacarbazine & $15.272 \pm 0.75$ & $15.218 \pm 0.81$ & $15.132 \pm 1.03$ & $14.95 \pm 1.45$ & $14.824 \pm 1.65$ \\
\hline & Eugenol & $44.392 \pm 1.4$ & $43.93 \pm 1.82$ & $42.30 \pm 3.04$ & $41.046 \pm 2.5$ & $40.174 \pm 3.67$ \\
\hline
\end{tabular}

To check the stability of liposomes in cell culture media (DMEM + 10\% FBS), lyophilized liposomes were also dispersed in it, and the above mentioned parameters were measured for three days. Liposomes retained their stability in cell culture media also (Table 8).

Table 8. Stability in Cell Culture Media (Eagle's minimal essential medium (DMEM) + 10\% FBS).

\begin{tabular}{|c|c|c|c|c|c|c|}
\hline \multicolumn{2}{|c|}{ Stability Parameters } & 0 Day & 1 Day & 2 Days & 3 Days & 4 Weeks \\
\hline \multicolumn{2}{|c|}{ Size (nm) } & $127.4 \pm 1.80$ & $132.64 \pm 4.69$ & $129.28 \pm 3.75$ & $134.61 \pm 2.57$ & $133.24 \pm 4.35$ \\
\hline \multicolumn{2}{|c|}{ PDI } & $0.175 \pm 0.068$ & $0.256 \pm 0.055$ & $0.222 \pm 0.072$ & $0.274 \pm 0.075$ & $0.302 \pm 0.890$ \\
\hline \multirow{2}{*}{$\begin{array}{c}\text { Drug } \\
\text { Content }(\%)\end{array}$} & Dacarbazine & $14.76 \pm 0.36$ & $14.48 \pm 0.32$ & $14.38 \pm 0.87$ & $14.15 \pm 1.06$ & $13.98 \pm 0.94$ \\
\hline & Eugenol & $42.45 \pm 2.50$ & $42.83 \pm 1.68$ & $41.32 \pm 2.11$ & $41.43 \pm 1.65$ & 41.57. \pm 0.79 \\
\hline
\end{tabular}

\subsection{Cell Line Studies}

\subsubsection{MTT Assay}

An MTT assay was performed to assess and compare the cytotoxic potential of the formulations. This test is based on the quantification of formazan dye which is produced after the metabolic cleavage of yellow tetrazolium salt MTT (3-(4,5-dimethylthiazol-2-yl)-2,5-diphenyl tetrazolium bromide assay) by alive cells [31]. First, the cytotoxicity of DEL was compared with DS and DL in SK-MEL-28 cells. As it was known that eugenol inhibits survivin protein, thereby inducing apoptosis and inhibiting 
angiogenesis, SK-MEL-28 cells were chosen because they overexpress survivin protein [35]. The amounts of formulations were introduced according to the amount of dacarbazine they contained. The different concentrations of dacarbazine (in each formulation) tested on SK-MEL-28 cells were $0.5 \mu \mathrm{g} / \mathrm{mL}$, $1 \mu \mathrm{g} / \mathrm{mL}, 5 \mu \mathrm{g} / \mathrm{mL}, 10 \mu \mathrm{g} / \mathrm{mL}, 12.5 \mu \mathrm{g} / \mathrm{mL}$, and $16.25 \mu \mathrm{g} / \mathrm{mL}$. Results of MTT assay in SK-MEL-28 cells are graphically represented in Figure 12. DS produced cytotoxicity of only $25.91 \pm 1.060 \%$ at a concentration of $16.25 \mu \mathrm{g} / \mathrm{mL}$, while DL at the same concentration of dacarbazine produced cytotoxicity of $35.89 \pm 1.109 \%$. In contrast to these, DEL produced cytotoxicity of $76.96 \pm 0.351 \%$ (at the same concentration of dacarbazine), which was more than double the cytotoxicity of DL. This suggests that eugenol is quite capable of potentiating the effect of dacarbazine on melanoma cells. This also indicates that combining eugenol with dacarbazine may allow a significant reduction of dacarbazine dose during chemotherapy. Since dacarbazine is a cytotoxic drug, reduction in its dose implies a reduction in unwanted toxicity on normal body cells.

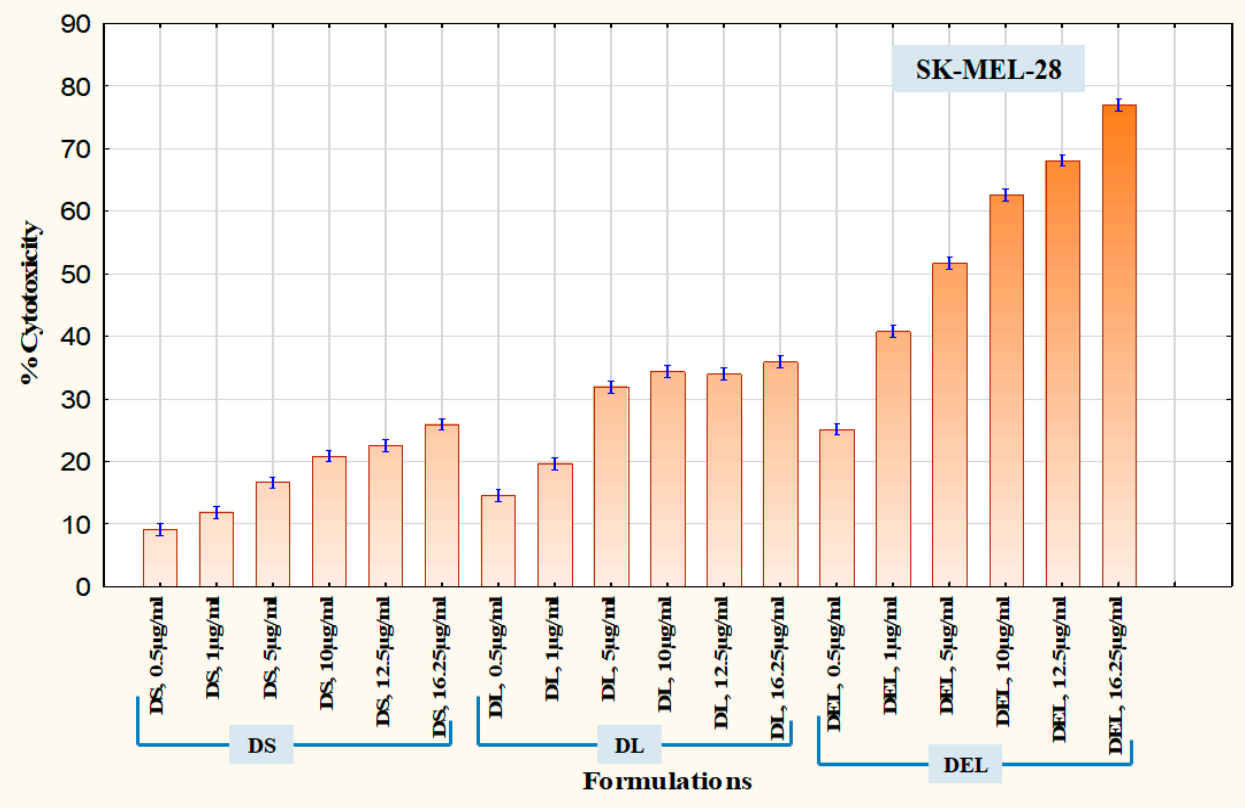

Figure 12. Cytotoxicity in SK-MEL-28 Melanoma Cells.

After SK-MEL-28 cells, B16F10 cells were employed to assess the therapeutic superiority of final formulation Dacarbazine + Eugenol Liposomes (DELC) over DS, DL, and DEL. B16F10 melanoma cells are also known to overexpress survivin and CD44 receptors [11,36]. Here the concentrations (of dacarbazine) tested were $0.05 \mu \mathrm{g} / \mathrm{mL}, 0.1 \mu \mathrm{g} / \mathrm{mL}, 0.5 \mu \mathrm{g} / \mathrm{mL}, 1 \mu \mathrm{g} / \mathrm{mL}, 5 \mu \mathrm{g} / \mathrm{mL}$, and $10 \mu \mathrm{g} / \mathrm{mL}$. Lower concentrations were tested this time because more potent action was expected from DELC. The results are presented in Figure 13. As can be observed, at a concentration of $0.05 \mu \mathrm{g} / \mathrm{mL}$, DS produced cytotoxicity of $3.60 \pm 0.055 \%$, while DELC produced cytotoxicity of $35.72 \pm 0.466 \%$. At a concentration of $0.5 \mu \mathrm{g} / \mathrm{mL}$, cytotoxicity of DS was only $10.20 \pm 0.288 \%$, whereas DELC produced $95.08 \pm 0.310 \%$ cytotoxicity. Therefore, our final coated liposomes of Dacarbazine and Eugenol showed enhancement of more than $900 \%$ in cytotoxicity, as compared to that of Dacarbazine Solution at the same concentration of dacarbazine $(0.5 \mu \mathrm{g} / \mathrm{mL})$ in both the formulations. Therefore, this concept of combining dacarbazine with eugenol, and encapsulating both the drugs in surface-functionalized liposomes (for better targeting and increased uptake), is capable of enabling oncologists to decrease the dose of dacarbazine several times. This can be a breakthrough in the chemotherapy of melanoma, as this will lead to better therapeutic outcomes with a much lesser dose of the cytotoxic agent and hence much lesser side effects. 


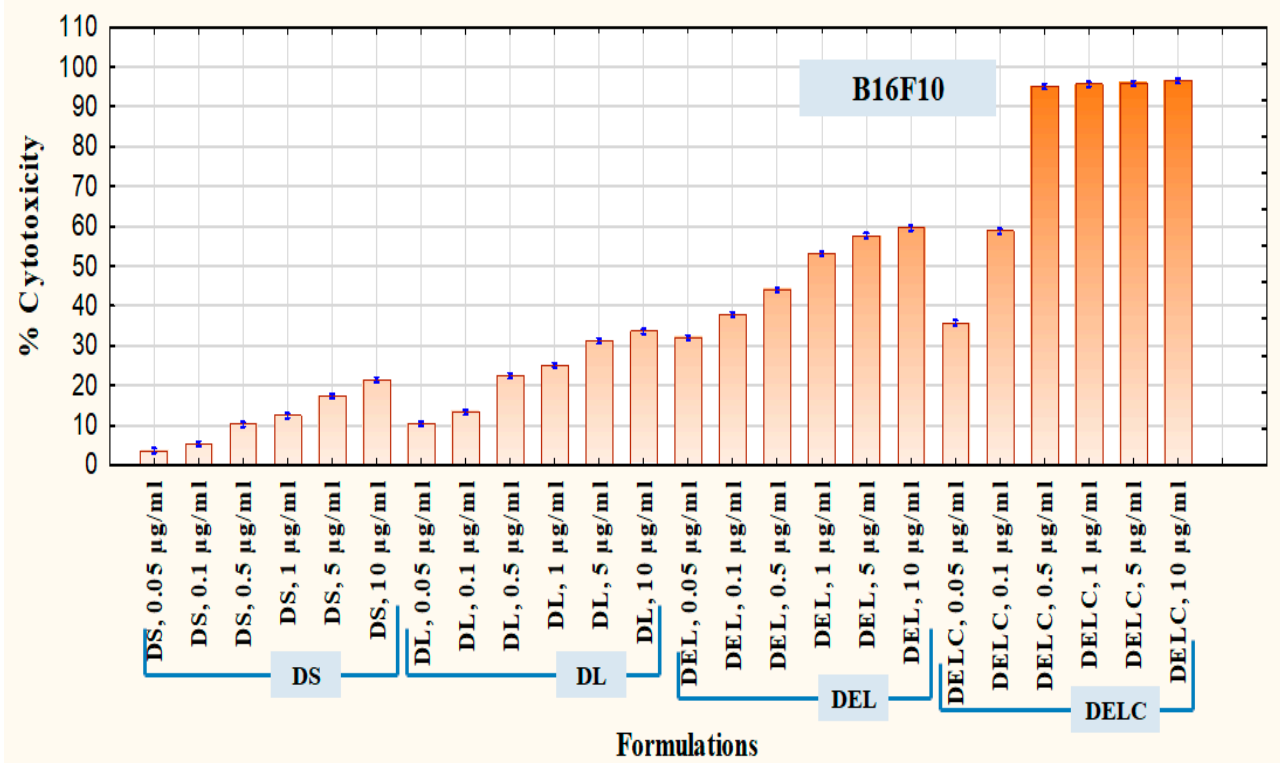

Figure 13. Cytotoxicity in B16F10 Melanoma Cells.

Cytotoxicity of blank liposomes was also assessed in both the cell lines to ascertain the safety of the carrier system (data not shown). The blank liposomes were found to be safe with no significant cytotoxicity.

\subsubsection{Apoptosis Assay}

Apoptosis caused by the formulations can be measured through a Phosphatidylserine (PS) assay. PS is normally located on the cytoplasmic face of the plasma membrane. During apoptosis, PS translocates to the outer leaflet of the plasma membrane, and can be detected by flow cytometry and cell imaging through binding to fluorochrome-labeled Annexin V when calcium is present [37]. An apoptosis assay was performed on SK-MEL-28 cells using an Annexin V kit. The concentration of dacarbazine in all the formulations was ten $\mu \mathrm{g} / \mathrm{mL}$. In DS treated cells, the percentage of viable, early apoptotic, late apoptotic and necrotic cells were $78.2 \pm 0.1,6.66 \pm 0.115 \%, 8.43 \pm 0.057 \%$ and $6.66 \pm 0.057 \%$ respectively. In the cells treated with DL, the percentage of early apoptotic, late apoptotic and necrotic cells were $17.2 \pm 0.1 \%, 23.2 \pm 0.1 \%$ and $5.3 \pm 0.2 \%$ respectively, while viable cells were $54.53 \pm 0.057 \%$. The viability of cells decreased to $38.3 \pm 0.1 \%$ when treated with DEL. Early apoptotic, late apoptotic and necrotic cells in the DEL-treated group were at $6.36 \pm 0.057 \%, 39.23 \pm 0.057 \%$ and $16.1 \pm 0 \%$. While the performance of DLC was slightly inferior to DEL, it performed much better than DL.

This can be owed to better uptake of liposomes by melanoma cells due to HA coating, and thus indicates towards the importance of surface functionalization. Furthermore, DELC caused maximum late apoptosis $(45.16 \pm 0.057 \%)$ and necrosis $(19.0 \pm 0.1 \%)$ out of all the formulations because of a better uptake of the liposomes which contained both dacarbazine and eugenol. So what can be concluded here is that the number of early apoptotic cells decreased (in addition to viability), while there was a significant increase in the number of late apoptotic and necrotic cells after the inclusion of Eugenol into the liposomes. Shibuya et al. had reported that Dacarbazine induced only apoptosis and no necrosis up to the concentration of $40 \mu \mathrm{g} / \mathrm{mL}$ [38]. In our study, also, Dacarbazine did not induce necrosis, as is evident by the fact that there is no significant difference in the number of necrotic cells in untreated, and DS- and DL-treated groups. However, there was a significant increase in the fraction of necrotic cells after coating of the liposomes, which implies that coating resulted in a higher concentration of dacarbazine reaching the cells. The increase was even higher after the inclusion of Eugenol. Results are represented in Figures 14 and 15. 


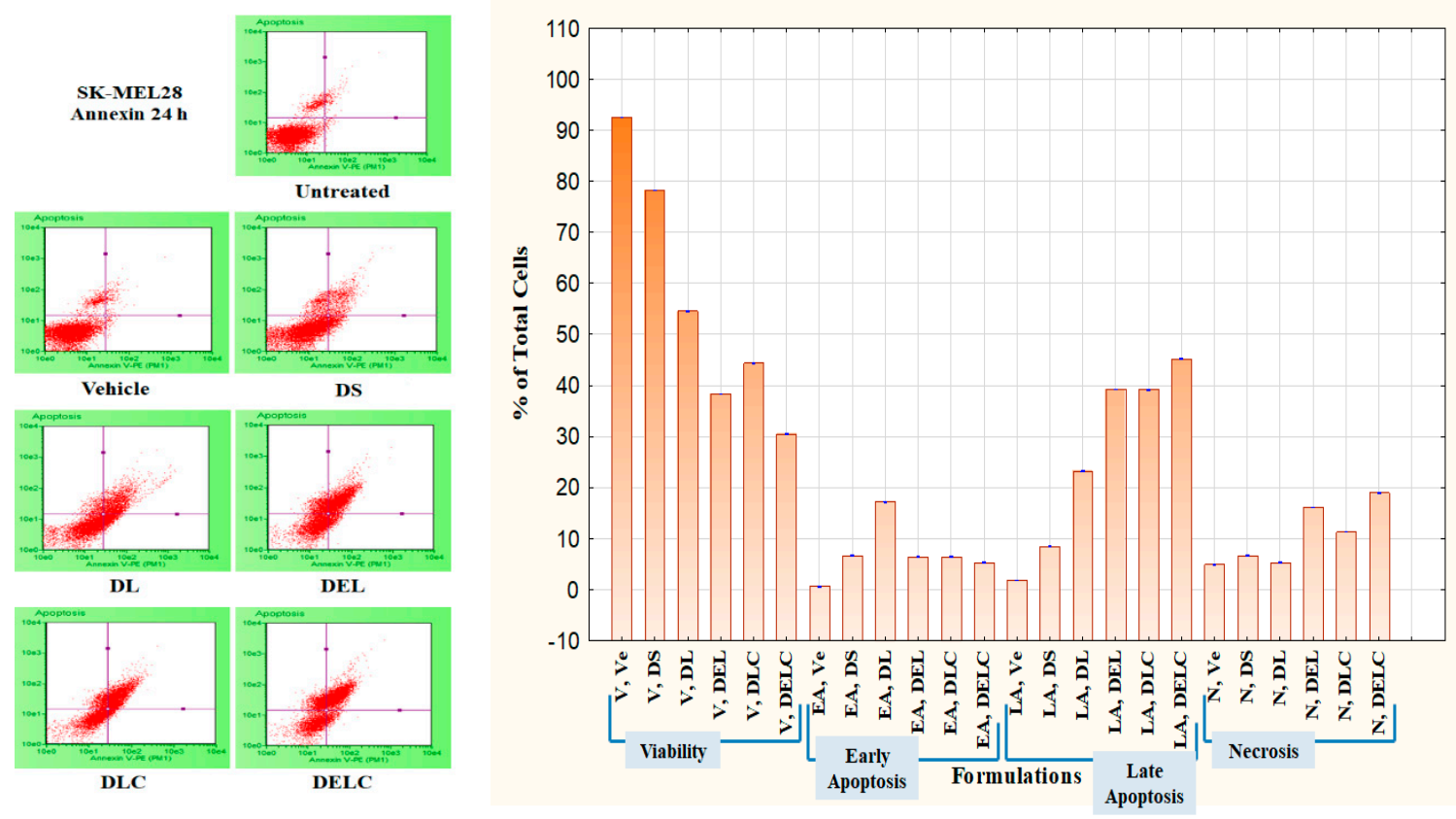

Figure 14. Apoptosis in SK-MEL-28 Melanoma cells.

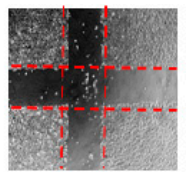

(a) Scratched at $0 \mathrm{~h}$

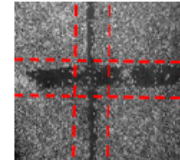

Untreated

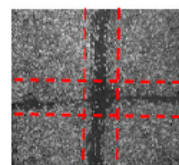

DL

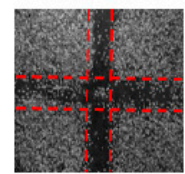

DLC

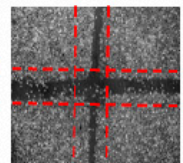

DS

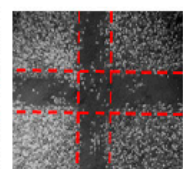

DEL

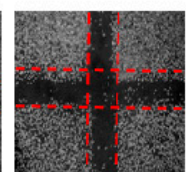

DELC

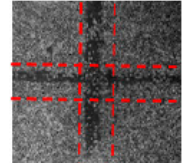

Untreated

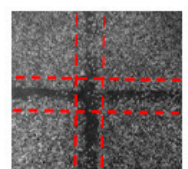

DL

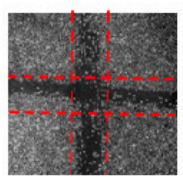

DLC

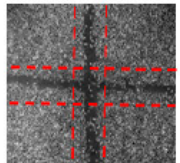

DS

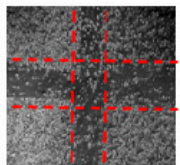

DEL

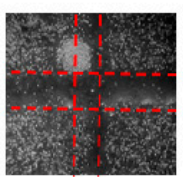

DELC

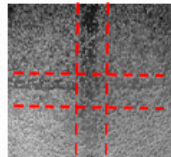

Untreated

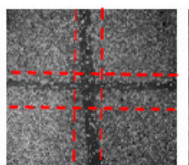

DL

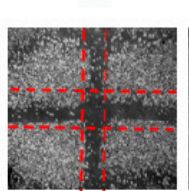

DLC

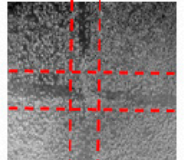

DS

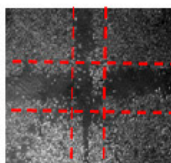

DEL

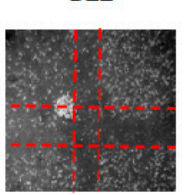

DELC

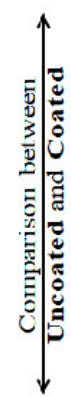

Comparison between Dacarbazine and

(b) $48 \mathrm{~h}$

(d) 72 h

(b) $24 \mathrm{~h}$

Figure 15. Migration in EA.hy926 cells.

Dacarbazine, which is an alkylating chemotherapeutic agent, mainly kills cancer cells by inducing apoptosis and necrosis [39]. However, its effects are not observed to a significant level of its potential, because of the anti-apoptotic ability of the cancer cells, which is imparted to them by survivin. Here, eugenol downregulated the survivin to inhibit the anti-apoptotic ability of melanoma cells. In the absence of survivin, dacarbazine released from the liposomes could exert its apoptotic and necrotic effects more efficiently. 


\subsubsection{Migration Assay}

Cell migration plays an important part in the invasion and metastasis of tumor to distant sites. Metastasis is a major complication of cancer, and is particularly more common in case of melanoma [40,41]. Melanoma, once metastasized, is almost always fatal [42]. Vascular endothelial cells play significant roles in many physiologically and pathologically important processes, and thus are commonly used to describe mechanisms of inflammation, angiogenesis, tumor growth, migration, and metastasis. EA.hy926 cell line, which is derived as the hybrid of primary human umbilical vein cells (HUVECs) and the continuous human lung carcinoma cell line A549, is presently the best characterized macro-vascular endothelial cell line [43]. Figures 15 and 16 present the results of the migration study performed on EA.hy926 cells. The values of '\% inhibition of migration' are calculated concerning untreated, i.e., the migration of untreated cells is assumed to be $100 \%$ (inhibition is $0 \%$ ), and all other values are relative to the migration of the untreated cells. The concentrations of DS, DL and DEL tested were $0.1 \mu \mathrm{g} / \mathrm{mL}$ and $1 \mu \mathrm{g} / \mathrm{mL}$, while concentrations of DLC and DELC tested were $0.01 \mu \mathrm{g} / \mathrm{mL}$ (data not shown), and $0.1 \mu \mathrm{g} / \mathrm{mL}$.

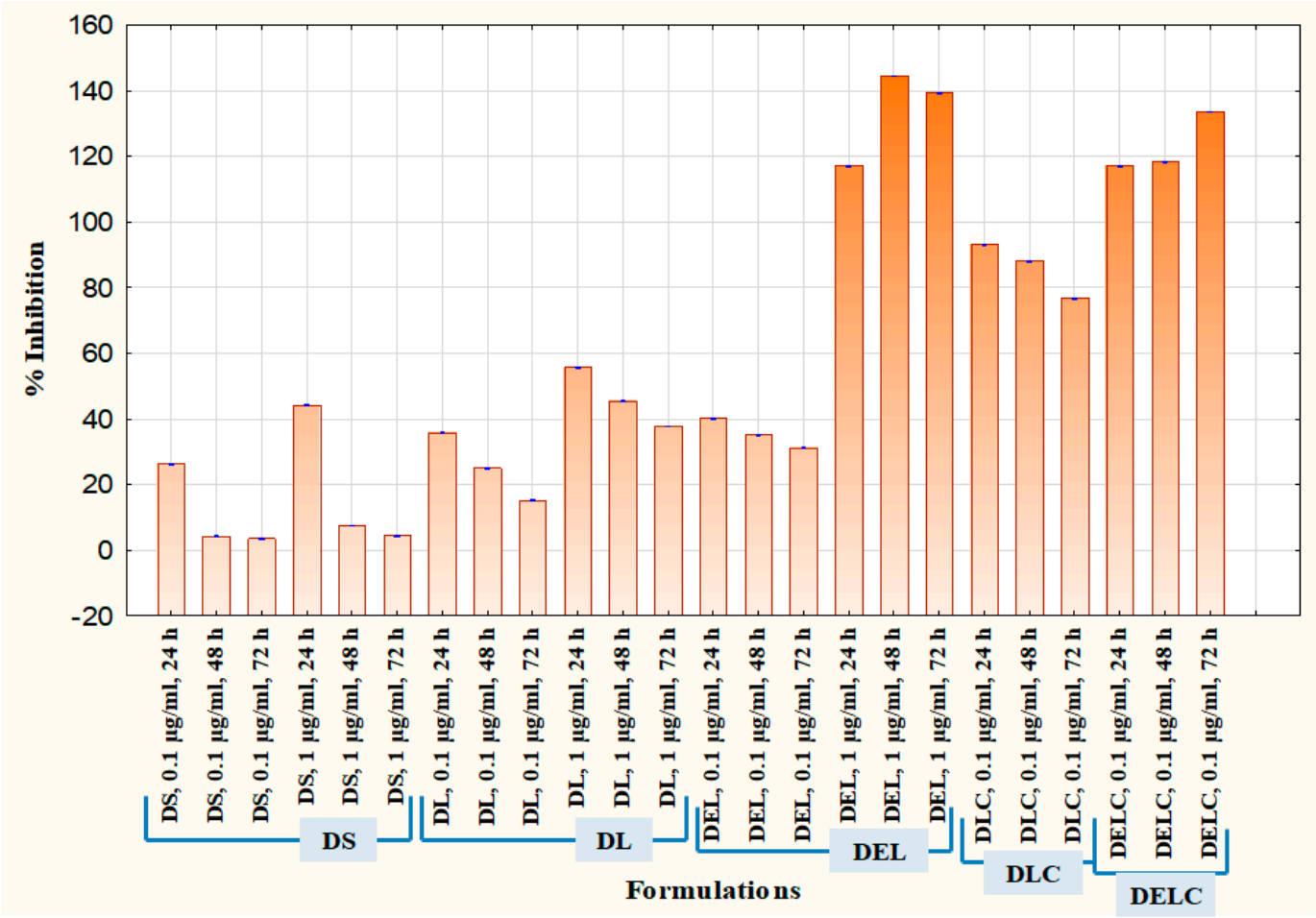

Figure 16. Migration assay in EA.hy926 cells.

At one $\mu \mathrm{g} / \mathrm{mL}$, DS showed an inhibition of $44.13 \pm 0.152 \%$ at $24 \mathrm{~h}$, which was quite significant, but inhibition drastically decreased to only $7.43 \pm 0.057 \%$ and $4.3 \pm 0.1 \%$ at $48 \mathrm{~h}$ and $72 \mathrm{~h}$ respectively. In the case of DL $(1 \mu \mathrm{g} / \mathrm{mL})$, inhibition was $55.66 \pm 0.115 \%, 45.43 \pm 0.152 \%$ and $37.73 \pm 0.057 \%$ at $24 \mathrm{~h}, 48 \mathrm{~h}$ and $72 \mathrm{~h}$, respectively. This indicates towards the somewhat sustained release of dacarbazine from DL, as the decrease in performance was not as steep as DS. In the DEL $(1 \mu \mathrm{g} / \mathrm{mL})$ treated group, there was a remarkable migration inhibition of $116.96 \pm 0.057 \%, 144.43 \pm 0.115 \%$ and $139.13 \pm 0.152 \%$ at three different time points. Here comes the role of eugenol, which has contributed significantly in inhibiting the migrating ability of the cells. As we can see, the \% inhibition has increased from $24 \mathrm{~h}$ to $48 \mathrm{~h}$, and then only slightly decreased at $72 \mathrm{~h}$, this indicates towards the more sustained release of the drugs. In the DLC $(0.1 \mu \mathrm{g} / \mathrm{mL})$ treated group, inhibition was $93.13 \pm 0.115 \%, 88.03 \pm 0.57 \%$ and $76.7 \pm 0.1 \%$. Here, the action was sustained for $72 \mathrm{~h}$, but not as much as in the case of DEL (inhibition has decreased rather than increasing). This shows that Eugenol plays a more significant role (than HA coating) in 
sustaining the release of dacarbazine. Inhibition in the cells treated with our final formulation DELC $(0.1 \mu \mathrm{g} / \mathrm{mL})$ was the highest; $116.86 \pm 0.057 \%, 118.26 \pm 0.115 \%$, and $133.53 \pm 0.0115 \%$.

It should be noted here that DELC gave similar results as DEL at a concentration one-tenth of it. This indicates that surface coating has improved the performance of the formulation by around ten times. Also, the inhibition continuously increased for $72 \mathrm{~h}$, which implies most sustained action out of all the formulations. It is because of the presence of both; the eugenol and the HA coating.

One interesting point to be noted here is that DLC has performed better than DEL (comparing results of $0.1 \mu \mathrm{g} / \mathrm{mL}$ ). This unexpected behavior can be attributed to the fact that EA.hy926 cells overexpress CD44 on the cell surface [44], and HA reportedly binds to EA.hy926 cells [45]. This must have resulted in better uptake of DLC as compared to DEL, which does not have HA coating to bind to CD44 receptors.

\subsubsection{Proliferation Assay}

Cell proliferation is the rapid increase in the number and amount of cells. Cytotoxic anti-cancer drugs kill cells that have a high basal level of proliferation and regeneration [46]. Thus, it is important to assess the effect of eugenol in the enhancement of proliferation when added to dacarbazine. It is usually more effective to test the antiangiogenic potential of pharmaceutical formulations on cells which have a substantial rate of proliferation [47], and so EA.hy926 cells were employed for the proliferation assay also. The results are graphically represented in Figure 17, where \% viability of cells after treatment with different formulations is denoted. Concentrations tested were $0.01 \mu \mathrm{g} / \mathrm{mL}$, $0.1 \mu \mathrm{g} / \mathrm{mL}, 0.5 \mu \mathrm{g} / \mathrm{mL}, 1 \mu \mathrm{g} / \mathrm{mL}, 2.5 \mu \mathrm{g} / \mathrm{mL}, 5 \mu \mathrm{g} / \mathrm{mL}$, and $10 \mu \mathrm{g} / \mathrm{mL}$. DS at dacarbazine concentration of $10 \mu \mathrm{g} / \mathrm{mL}$ reduced the viability of cells to $77.31 \pm 0.47$, while DL reduced it to $58.83 \pm 0.610 \%$. When eugenol was co-loaded with dacarbazine in the liposomes (DEL), the cell viability decreased to $34.46 \pm 0.643 \%$ at ten $\mu \mathrm{g} / \mathrm{mL}$. The viability of cells treated with DLC $(10 \mu \mathrm{g} / \mathrm{mL})$ was $27.08 \pm 0.605 \%$, which was a little less than DEL because of the same reason as stated above. Most interestingly, the coated liposomes of Dacarbazine and Eugenol (DELC) left only $6.14 \pm 0.618 \%$ cells viable. The anti-proliferative performance of DELC was much more significant than DS, which is the conventional way of how the dacarbazine is administered.

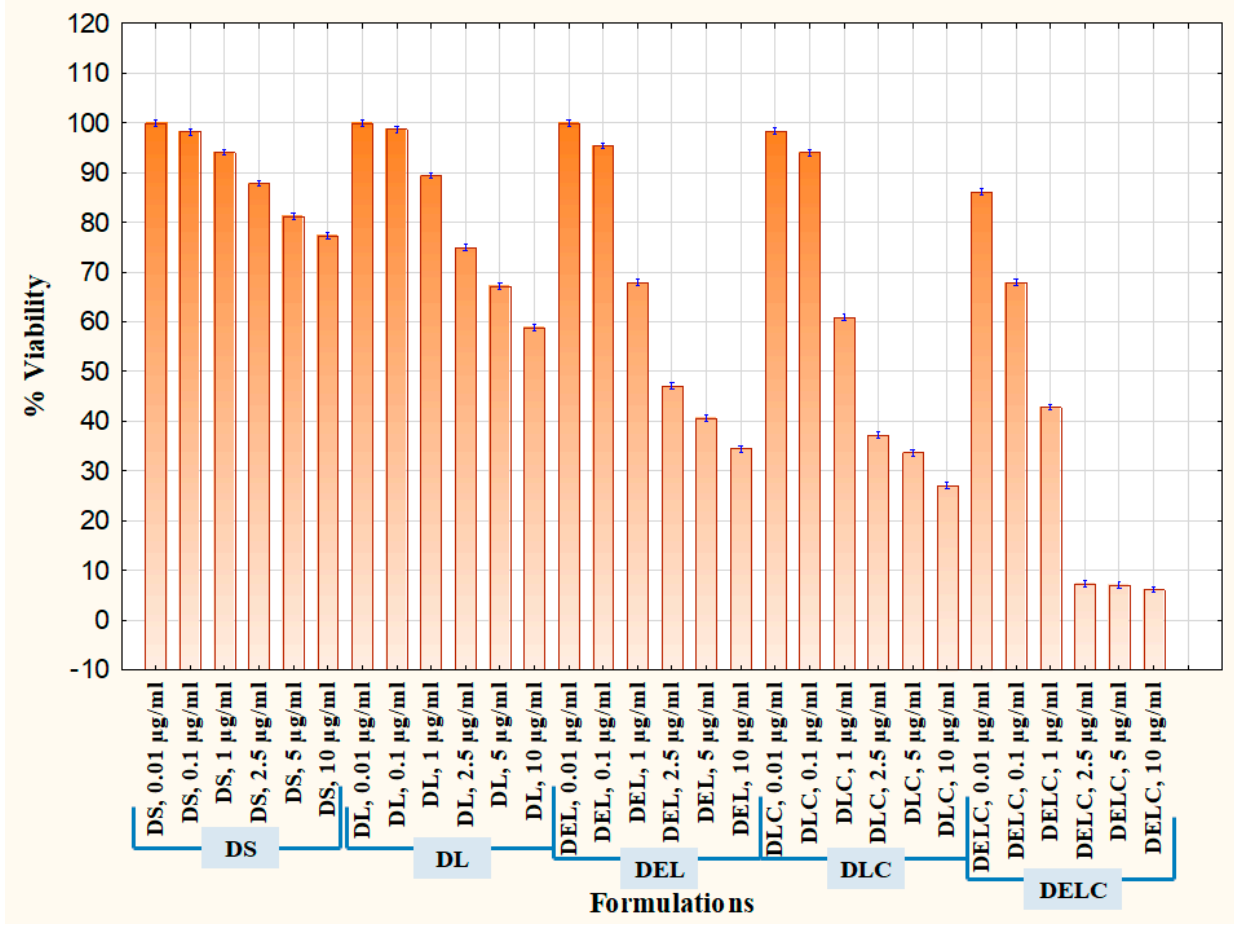

Figure 17. Proliferation Assay in EA.hy926 cells. 


\section{Conclusions}

Keeping the highly resistant and aggressive nature of melanoma in mind, dacarbazine- and eugenol-loaded liposomes were successfully developed for a combinatorial approach against melanoma. The $\mathrm{QbD}$ approach enabled us to synthesize the said anti-melanoma formulation with optimum parameters in the most logical manner. Applying this $\mathrm{QbD}$ approach at two levels further made the process easier to reproduce, and more cost-effective. Surface functionalization of the formulation made the entire therapy more targeted to spare normal body cells from unwanted toxicity. In-vitro characterization of the nanoliposomes ascertained the utility of the QbD application. This work is a good example and illustration of the successful application and value of the quality by design approach in the development of effective pharmaceutical nanoformulations.

The performance of the formulation as an anti-melanoma agent was assessed by cell line studies. Combining eugenol with dacarbazine resulted in much higher anti-melanoma activity of the formulation. This enhancement is supposed to be due to the inhibition of the anti-apoptotic protein surviving, which is overexpressed in the melanoma cells, and makes them resistant towards apoptosis. Including Eugenol resulted in a downregulation of survivin protein, consequent to which, dacarbazine could perform its function to its maximum potential. This resulted in significantly higher cytotoxicity, increased apoptosis, and much decreased migration and proliferation of the cancer cells. Thus, the combination of dacarbazine and eugenol holds the promise of overcoming the resistance of melanoma cells and any challenges of anti-melanoma therapies. In addition to increased apoptosis and cytotoxicity, this combination also promises to inhibit the metastatic potential of the melanoma.

Since this study has strongly indicated that survivin is inhibited in the presence of eugenol, the result of which is that dacarbazine could perform better, this opens up the scope of analyzing the survivin expression of the melanoma cells before and after treatment. Also, the efficacy of this novel approach can be tested in the in-vivo model to ascertain its applicability. Therefore, survivin expression studies and in-vivo studies can be future prospects to support the importance of the above-mentioned results and inferences.

Author Contributions: Conceptualization, H.M. and P.K.M.; Formal analysis, P.K.M.; Funding acquisition, H.M.; Investigation, H.M., A.M., K.B., N.G. (Namita Gupta), N.G. (Neha Gupta), K.V. and R.V.; Methodology, Z.I., A.M., R.V. and S.T.; Project administration, Z.I., M.J. and S.T.; Resources, M.J., R.V. and S.T.; Supervision, Z.I., M.J. and S.T.; Validation, S.T.; Writing—original draft, H.M.; Writing—review \& editing, P.K.M.

Funding: This research was funded by ICMR grant number 45/67/2018-Nan/BMS.

Acknowledgments: The Authors are thankful to Intas Pharmaceuticals for providing Dacarbazine was and to Lipoid, Germany for providing lipid.

Conflicts of Interest: The authors declare no conflict of interest.

\section{References}

1. Sadozai, H.; Gruber, T.; Hunger, R.E.; Schenk, M. Recent Successes and Future Directions in Immunotherapy of Cutaneous Melanoma. Front. Immunol. 2017, 8, 1617. [CrossRef] [PubMed]

2. Bandarchi, B.; Jabbari, C.A.; Vedadi, A.; Navab, R. Molecular biology of normal melanocytes and melanoma cells. J. Clin. Pathol. 2013, 66, 644-648. [CrossRef] [PubMed]

3. Fitzmaurice, C.; Allen, C.; Barber, R.M.; Barregard, L.; Bhutta, Z.A.; Brenner, H.; Dicker, D.J.; Chimed-Orchir, O.; Dandona, R.; Dandona, L. Global, regional, and national cancer incidence, mortality, years of life lost, years lived with disability, and disability-adjusted life-years for 32 cancer groups, 1990 to 2015: A systematic analysis for the global burden of disease study. JAMA Oncol. 2017, 3, 524-548. [PubMed]

4. Bhatia, S.; Tykodi, S.S.; Thompson, J.A. Treatment of Metastatic Melanoma: An Overview. Oncol. Williston Park N 2009, 23, 488-496.

5. Mishra, H.; Mishra, P.K.; Ekielski, A.; Jaggi, M.; Iqbal, Z.; Talegaonkar, S. Melanoma treatment: From conventional to nanotechnology. J. Cancer Res. and Clin. Oncol. 2018, 144, 2283-2302. [CrossRef] 
6. Mishra, H.; Mishra, P.K.; Ekielski, A.; Iqbal, Z.; Jaggi, M.; Talegaonkar, S. Functionalized nanoliposomes loaded with anti survivin and anti angiogenic agents to enhance the activity of chemotherapy against melanoma by 4-pronged action. Med. Hypotheses 2018, 116, 141-146. [CrossRef] [PubMed]

7. Kesharwani, S.S.; Kaur, S.; Tummala, H.; Sangamwar, A.T. Overcoming multiple drug resistance in cancer using polymeric micelles. Expert Opin. Drug Deliv. 2018, 15, 1127-1142. [CrossRef]

8. Kesharwani, S.S.; Kaur, S.; Tummala, H.; Sangamwar, A.T. Multifunctional approaches utilizing polymeric micelles to circumvent multidrug resistant tumors. Colloids Surf. B Biointerfaces 2019, 173, 581-590. [CrossRef]

9. Grossman, D.; McNiff, J.M.; Li, F.; Altieri, D.C. Expression and targeting of the apoptosis inhibitor, survivin, in human melanoma. J. Investig. Dermatol. 1999, 113, 1076-1081. [CrossRef]

10. Helmbach, H.; Rossmann, E.; Kern, M.A.; Schadendorf, D. Drug-resistance in human melanoma. Int. J. Cancer 2001, 93, 617-622. [CrossRef]

11. Fernández, J.G.; Rodríguez, D.A.; Valenzuela, M.; Calderon, C.; Urzúa, U.; Munroe, D.; Rosas, C.; Lemus, D.; Díaz, N.; Wright, M.C. Survivin expression promotes VEGF-induced tumor angiogenesis via PI3K/Akt enhanced $\beta$-catenin/Tcf-Lef dependent transcription. Mol. Cancer 2014, 13, 209. [CrossRef]

12. Yamanaka, K.; Nakahara, T.; Yamauchi, T.; Kita, A.; Takeuchi, M.; Kiyonaga, F.; Kaneko, N.; Sasamata, M. Antitumor activity of YM155, a selective small-molecule survivin suppressant, alone and in combination with docetaxel in human malignant melanoma models. Clin. Cancer Res. 2011, 17, 5423-5431. [CrossRef] [PubMed]

13. Ma, W.-H.; Liu, Y.-C.; Xue, M.-L.; Zheng, Z.; Ge, Y.-L. Downregulation of survivin expression exerts antitumoral effects on mouse breast cancer cells in vitro and in vivo. Oncol. Lett. 2016, 11, 159-167. [CrossRef]

14. Zhang, M.; Sun, Y.-F.; Luo, S. Ani-survivin DNAzymes inhibit cell proliferation and migration in Breast Cancer Cell Line MCF-7. Asian Pac. J. Cancer Prev. 2012, 13, 6233-6237. [CrossRef]

15. Al-Sharif, I.; Remmal, A.; Aboussekhra, A. Eugenol triggers apoptosis in breast cancer cells through E2F1/survivin down-regulation. BMC Cancer 2013, 13, 600. [CrossRef] [PubMed]

16. Slameňová, D.; Horváthová, E.; Wsólová, L.; Šramková, M.; Navarová, J. Investigation of anti-oxidative, cytotoxic, DNA-damaging and DNA-protective effects of plant volatiles eugenol and borneol in human-derived HepG2, Caco-2 and VH10 cell lines. Mutat. Res. Toxicol. Environ. Mutagen. 2009, 677, 46-52. [CrossRef] [PubMed]

17. Carrasco, A.H.; Espinoza, C.L.; Cardile, V.; Gallardo, C.; Cardona, W.; Lombardo, L.; Catalán, M.K.; Cuellar, F.M.; Russo, A. Eugenol and its synthetic analogues inhibit cell growth of human cancer cells (Part I). J. Braz. Chem. Soc. 2008, 19, 543-548. [CrossRef]

18. Mitra, A.K.; Agrahari, V.; Mandal, A.; Cholkar, K.; Natarajan, C.; Shah, S.; Joseph, M.; Trinh, H.M.; Vaishya, R.; Yang, X.; et al. NOVEL DELIVERY APPROACHES FOR CANCER THERAPEUTICS. J. Control. Release Off. J. Control. Release Soc. 2015, 219, 248-268. [CrossRef]

19. Wickens, J.M.; Alsaab, H.O.; Kesharwani, P.; Bhise, K.; Amin, M.C.I.M.; Tekade, R.K.; Gupta, U.; Iyer, A.K. Recent advances in hyaluronic acid-decorated nanocarriers for targeted cancer therapy. Drug Discov. Today 2017, 22, 665-680. [CrossRef]

20. Wang, Y.; Yang, F.; Zhang, H.-X.; Zi, X.-Y.; Pan, X.-H.; Chen, F.; Luo, W.-D.; Li, J.-X.; Zhu, H.-Y.; Hu, Y.-P. Cuprous oxide nanoparticles inhibit the growth and metastasis of melanoma by targeting mitochondria. Cell Death Dis. 2013, 4, e783. [CrossRef]

21. Camerin, M.; Moreno, M.; Marín, M.J.; Schofield, C.L.; Chambrier, I.; Cook, M.J.; Coppellotti, O.; Jori, G.; Russell, D.A. Delivery of a hydrophobic phthalocyanine photosensitizer using PEGylated gold nanoparticle conjugates for the in vivo photodynamic therapy of amelanotic melanoma. Photochem. Photobiol. Sci. 2016, 15, 618-625. [CrossRef]

22. Deng, C.; Zhang, Q.; Fu, Y.; Sun, X.; Gong, T.; Zhang, Z. Coadministration of Oligomeric Hyaluronic Acid-Modified Liposomes with Tumor-Penetrating Peptide-iRGD Enhances the Antitumor Efficacy of Doxorubicin against Melanoma. ACS Appl. Mater. Interfaces 2017, 9, 1280-1292. [CrossRef] [PubMed]

23. Yu, L.X. Pharmaceutical Quality by Design: Product and Process Development, Understanding, and Control. Pharm. Res. 2008, 25, 781-791. [CrossRef] [PubMed] 
24. Xu, X.; Khan, M.A.; Burgess, D.J. A quality by design (QbD) case study on liposomes containing hydrophilic API: I. Formulation, processing design and risk assessment. Int. J. Pharm. 2011, 419, 52-59. [CrossRef] [PubMed]

25. Senbanjo, L.T.; Chellaiah, M.A. CD44: A Multifunctional Cell Surface Adhesion Receptor Is a Regulator of Progression and Metastasis of Cancer Cells. Front. Cell Dev. Biol. 2017, 5, 18. [CrossRef] [PubMed]

26. Sebaaly, C.; Jraij, A.; Fessi, H.; Charcosset, C.; Greige-Gerges, H. Preparation and characterization of clove essential oil-loaded liposomes. Food Chem. 2015, 178, 52-62. [CrossRef]

27. Kumar, S.; Ali, J.; Baboota, S. Design Expert ${ }^{\circledR}$ supported optimization and predictive analysis of selegiline nanoemulsion via the olfactory region with enhanced behavioural performance in Parkinson's disease. Nanotechnology 2016, 27, 435101. [CrossRef]

28. Negi, L.M.; Jaggi, M.; Joshi, V.; Ronodip, K.; Talegaonkar, S. Hyaluronan coated liposomes as the intravenous platform for delivery of imatinib mesylate in MDR colon cancer. Int. J. Biol. Macromol. 2015, 73, 222-235. [CrossRef]

29. Muley, P.; Kumar, S.; El Kourati, F.; Kesharwani, S.S.; Tummala, H. Hydrophobically modified inulin as an amphiphilic carbohydrate polymer for micellar delivery of paclitaxel for intravenous route. Int. J. Pharm. 2016, 500, 32-41. [CrossRef]

30. Kumar, S.; Kesharwani, S.S.; Mathur, H.; Tyagi, M.; Bhat, G.J.; Tummala, H. Molecular complexation of curcumin with $\mathrm{pH}$ sensitive cationic copolymer enhances the aqueous solubility, stability and bioavailability of curcumin. Eur. J. Pharm. Sci. 2016, 82, 86-96. [CrossRef]

31. Sharma, H.; Kumar, K.; Choudhary, C.; Mishra, P.K.; Vaidya, B. Development and characterization of metal oxide nanoparticles for the delivery of anticancer drug. Artif. Cells Nanomed. Biotechnol. 2016, 44, 672-679. [CrossRef] [PubMed]

32. Jaafar-Maalej, C.; Diab, R.; Andrieu, V.; Elaissari, A.; Fessi, H. Ethanol injection method for hydrophilic and lipophilic drug-loaded liposome preparation. J. Liposome Res. 2010, 20, 228-243. [CrossRef]

33. Lasic, D.D. The mechanism of vesicle formation. Biochem. J. 1988, 256, 1-11. [CrossRef]

34. Ghosh, R.; Nadiminty, N.; Fitzpatrick, J.E.; Alworth, W.L.; Slaga, T.J.; Kumar, A.P. Eugenol causes melanoma growth suppression through inhibition of E2F1 transcriptional activity. J. Biol. Chem. 2005, 280, 5812-5819. [CrossRef] [PubMed]

35. Chen, Y.; Kramer, D.L.; Li, F.; Porter, C.W. Loss of inhibitor of apoptosis proteins as a determinant of polyamine analog-induced apoptosis in human melanoma cells. Oncogene 2003, 22, 4964. [CrossRef] [PubMed]

36. Mummert, M.E.; Mummert, D.I.; Ellinger, L.; Takashima, A. Functional Roles of Hyaluronan in B16-F10 Melanoma Growth and Experimental Metastasis in Mice1. Mol. Cancer Ther. 2003, 2, 295-300. [PubMed]

37. Prieto, V.G.; Sadick, N.S.; Shea, C.R. Androgenetic Alopecia: Analysis of Proliferation and Apoptosis. Arch. Dermatol. 2002, 138, 1101-1102. [CrossRef]

38. Shibuya, H.; Kato, Y.; Saito, M.; Isobe, T.; Tsuboi, R.; Koga, M.; Toyota, H.; Mizuguchi, J. Induction of apoptosis and/or necrosis following exposure to antitumour agents in a melanoma cell line, probably through modulation of Bcl-2 family proteins. Melanoma Res. 2003, 13, 457-464. [CrossRef]

39. Sanada, M.; Hidaka, M.; Takagi, Y.; Takano, T.Y.; Nakatsu, Y.; Tsuzuki, T.; Sekiguchi, M. Modes of actions of two types of anti-neoplastic drugs, dacarbazine and ACNU, to induce apoptosis. Carcinogenesis 2007, 28, 2657-2663. [CrossRef]

40. Feng, T.; Yu, H.; Xia, Q.; Ma, Y.; Yin, H.; Shen, Y.; Liu, X. Cross-talk mechanism between endothelial cells and hepatocellular carcinoma cells via growth factors and integrin pathway promotes tumor angiogenesis and cell migration. Oncotarget 2017, 8, 69577-69593. [CrossRef]

41. McKenzie, J.A.; Liu, T.; Goodson, A.; Grossman, D. Survivin enhances motility of melanoma cells by supporting Akt activation and $\alpha 5$ integrin upregulation. Cancer Res. 2010, 70, 7927-7937. [CrossRef] [PubMed]

42. Tas, F. Metastatic Behavior in Melanoma: Timing, Pattern, Survival, and Influencing Factors. Available online: https://www.hindawi.com/journals/jo/2012/647684/ (accessed on 27 September 2018).

43. Expression of Integrins and Adhesive Properties of Human Endothelial Cell Line EA.hy 926. Available online: http://cgp.iiarjournals.org/content/2/5/265.abstract (accessed on 12 September 2018). 
44. El-Dakdouki, M.H.; El-Boubbou, K.; Kamat, M.; Huang, R.; Abela, G.S.; Kiupel, M.; Zhu, D.C.; Huang, X. CD44 Targeting Magnetic Glyconanoparticles for Atherosclerotic Plaque Imaging. Pharm. Res. 2014, 31, 1426. [CrossRef] [PubMed]

45. Alam, C.; Seed, M.; Freemantle, C.; Brown, J.; Perretti, M.; Carrier, M.; Divwedi, A.; West, D.; Gustafson, S.; Colville-Nash, P. The inhibition of neutrophil-endothelial cell adhesion by hyaluronan independent of CD44. Inflammopharmacology 2005, 12, 535-550. [CrossRef] [PubMed]

46. Feitelson, M.A.; Arzumanyan, A.; Kulathinal, R.J.; Blain, S.W.; Holcombe, R.F.; Mahajna, J.; Marino, M.; Martinez-Chantar, M.L.; Nawroth, R.; Sanchez-Garcia, I.; et al. Sustained proliferation in cancer: Mechanisms and novel therapeutic targets. Semin. Cancer Biol. 2015, 35, S25-S54. [CrossRef]

47. Adair, T.H.; Montani, J.-P. Angiogenesis Assays; Morgan \& Claypool Life Sciences: San Rafael, CA, USA, 2010.

(C) 2019 by the authors. Licensee MDPI, Basel, Switzerland. This article is an open access article distributed under the terms and conditions of the Creative Commons Attribution (CC BY) license (http://creativecommons.org/licenses/by/4.0/). 